DOE/ID/01523--4

DE84 010394

\title{
DIRECT CONTACT CONDENSATION OF IMMISCIBLE FLUIDS IN PACKED BEDS
}

\author{
K. D. Thomas \\ H. R. Jacobs \\ R. F. Boehm \\ avallabie copy to permit the broadest \\ jossible avaHlablitity.
}

\author{
MECHANICAL ENGINEERING \\ UNIVERSITY OF UTAH \\ SALT LAKE CITY, UTAH 84112 \\ Date Published--November 1978 \\ As07-76 \& 001523
}

\section{ENERGY RESEARCH AND DEVELOPMENT ADMINISTRATION \\ DIVISION OF GEOTHERI!AL ENERGY \\ UNDER CONTRACT NO. E(10-1)1523}




\section{DISCLAIMER}

This report was prepared as an account of work sponsored by an agency of the United States Government. Neither the United States Government nor any agency Thereof, nor any of their employees, makes any warranty, express or implied, or assumes any legal liability or responsibility for the accuracy, completeness, or usefulness of any information, apparatus, product, or process disclosed, or represents that its use would not infringe privately owned rights. Reference herein to any specific commercial product, process, or service by trade name, trademark, manufacturer, or otherwise does not necessarily constitute or imply its endorsement, recommendation, or favoring by the United States Government or any agency thereof. The views and opinions of authors expressed herein do not necessarily state or reflect those of the United States Government or any agency thereof. 


\section{DISCLAIMER}

Portions of this document may be illegible in electronic image products. Images are produced from the best available original document. 


\begin{abstract}
An experimental study of a film type direct contact heat exchanger using immiscible fluids is made. Laboratory experiments were conducted on a R-113 - water system using both $2.5 \mathrm{~cm}$ Berl saddles and $3.2 \mathrm{~cm}$ spheres as packing, in a $14.6 \mathrm{~cm}$ diameter column. The configuration was counter flow, with the vapor phase entering at the base of the column, and condensing on the laminar water film that coated the packing surface. Packing height, water temperature and both water and vapor flow rates were varied in obtaining heat transfer data. These and other packed bed heat transfer data published in the literature were reduced and correlated to yield a relationship between the Stanton number and the important vessel operating parameters.
\end{abstract}

\title{
DISCLAIMER
}

This report was prepared as an account of work sponsored by an agency of the United States Government. Neither the United States Government nor any agency thereof, nor any of their employees, makes any warranty, express or implied, or assumes any legal liability or responsibility for the accuracy, completeness, or usefulness of any information, apparatus, product, or process disclosed, or represents that its use would not infringe privately owned rights. Reference herein to any specific commercial product, process, or service by trade name, trademark, manufacturer, or otherwise does not necessarily constitute or imply its endorsement, recommendation, or favoring by the United States Government or any agency thereof. The views and opinions of authors expressed herein do not necessarily state or reflect those of the United States Government or any agency thereof. 


\section{TABLE OF CONTENTS}

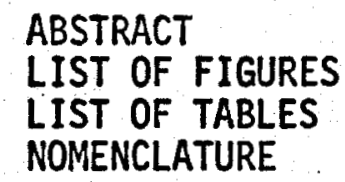

Page

I. INTRODUCTION 1

II. PREVIOUS WORK 4

III. DERIVATION OF BASIC EQUATIONS 14

A. Definition of HTU, NTU and St 14

B. Penetration Theory 16

C. Theoretical Approach 18

IV. EXPERIMENTAL APPARATUS AND PROCEDURE 20

A. Test Apparatus $\quad 20$

1. System 20

2. Condenser 22

3. Primary Separator 26

4. Water Inlet Manifold 29

B. Experimental Procedure 29

v. DISCUSSION OF RESULTS 33

A. Correlation Equation 33

1. Stanton Number Dependence on Jakob Number 34

2. Stanton Number Dependence on Heat Capacity 34

3. Stanton Number Dependence on Bed Height $\quad 39$

4. Determination of Proportional ity Constants 39

B. Comments on the Correlation Equation $\quad 49$

C. Comparison with Previous Work $\quad 50$

D. Simplified Penetration Theory Results 57 
VI. CONCLUSIONS

Page

VII. SUGGESTIONS FOR FUTURE WORK

60

APPENDIX I DATA REDUCTION

A. Data Reduction Procedure

B. Computer Routine 


\section{LIST OF FIGURES}

Figure

Page

1 Schematic of System for Direct Contact Condensation of $R-113$

2 Schematic of Test Vesse1 23

3 Test Vessel 24

4 Schematic of Primary Separator 27

5 Primary Separator 28

6 Construction Details of Water Spray Manifold 30

7 Spray Manifold and Water Inlet Assembly 31

8 Spray Manifold Interior 31

9 Effect of Ja on St for R-113 - water System 35 Using $3.2 \mathrm{~cm}$ Diameter Spherical Packing

10 Effect of Ja on St for R-113 - water System 36 Using $2.5 \mathrm{~cm}$ Berl Saddle Packing.

11 Effect of Ja on St for Steam Condensing on Aroclor 37 in a 66 High Bed of $2.5 \mathrm{~cm}$ Raschig Rings

12 Effect of Ja on St for Steam Condensing on Aroclor in a 96 High Bed of $2.5 \mathrm{~cm}$ Raschig Rings

13 Effect of Hourly Heat Capacity Ratio on St/Ja for R-113 - water System Data Using $3.2 \mathrm{~cm}$ Diameter Spherical Packing

14 Effect of Hourly Heat Capacity Ratio on St/Ja for R-113 - water System Data Using $2.5 \mathrm{~cm}$ Berl Saddle Packing

15 Effect of Hourly Heat Capacity Ratio on St/Ja for Aroclor-Steam System Using $2.5 \mathrm{~cm}$ Raschig Ring Packing 
Figure

16 Correlation of Data with Respect to Non-dimensional Height $H$

17 Effect of $H$ on Stanton Number for R-113 - water System 44 Using $32 \mathrm{~cm}$ Spherical Packing

18 Effect of $H$ on Stanton Number for R-113 - water System 45 Using $2.5 \mathrm{~cm}$ Berl Saddle Packing

19 Effect of Liquid Phase Flow Rate on ha for R-113 water ha for R-113 - water System

20. Effect of Liquid Phase Flow Rate on ha for R-113 water System

21 Effect of Liquid Phase Flow Rate on ha for R-113 water System

22 Effect of Liquid Phase Flow Rate on ha for R-113 water System

23 Effect of Liquid Phase Flow Rate on ha for R-113water System

24 Effect of Liquid Phase Flow Rate on ha for $R-113$ water System

25 Qualitative Temperature Distribution in a Packed Bed Condenser 


\section{LIST OF TABLES}

Table

Page

1 Variables Used in Computer Routine 65

2 Experimental Data $3.2 \mathrm{~cm}$ Spherical Packing ... 68

3 Experimental Data $2.5 \mathrm{~cm}$ Berl Saddle Packing $\quad 70$

$4 \quad$ Calculated Experimental Results $3.2 \mathrm{~cm} \quad 71$

5 Calculated Experimental Results $2.5 \mathrm{~cm} \mathrm{Berl} 73$ Saddle Packing 


\section{NOMENCLATURE}

a Total surface area of packing per unit volume, $\mathrm{m}^{2} / \mathrm{m}^{3}$

$a_{w} \quad$ Wetted surface of packing, $\mathrm{m}^{2}$

$a_{t} \quad$ Total surface area of packing, $\mathrm{m}^{2}$

A Cross-sectional area of tower, $\mathrm{m}^{2}$

$C_{p} \quad$ Constant-pressure specific heat, $\mathrm{J} /\left(\mathrm{kg} \cdot{ }^{\circ} \mathrm{C}\right)$

C Ratio of hourly heat capacities, dimensionless

c Concentration, $\mathrm{kg}$-moles $/ \mathrm{m}^{3}$

d Sphere diameter, $\mathrm{cm}$

D Diffusivity coefficient for mass transfer, $\mathrm{m}^{2} / \mathrm{h}$

F Fraction of free volume in packing, $\mathrm{m}^{3} /\left(\mathrm{m}^{3}\right.$ tower volume)

g Gravitational constant, $\mathrm{m} / \mathrm{s}^{2}$

$G$ Vapor mass flow rate per unit column cross section, $\mathrm{kg} /\left(\mathrm{h} \cdot \mathrm{m}^{2}\right)$

h Local heat transfer coefficient, $W /\left(\mathrm{m}^{2} \cdot{ }^{\circ} \mathrm{C}\right)$

$\bar{h} \quad$ Average heat transfer coefficient, $W /\left(m^{2} \cdot{ }^{\circ} \mathrm{C}\right)$

H Non-dimensional bed height

ha Overall volumetric heat transfer coefficient, $W /\left(m^{3} \cdot{ }^{\circ} \mathrm{C}\right)$

HTU Heigh of a transfer unit, $\mathrm{cm}$

Ja Jakob number, dimensionless

$k \quad$ Thermal conductivity, $W /\left(m \cdot{ }^{\circ} \mathrm{C}\right)$

$K_{L} \quad$ Liquid film mass transfer coefficient, $\mathrm{kg}-$ moles $/\left[\mathrm{m}^{2}-\mathrm{h}\right.$ (unit concentration)] 
l. Volumetric liquid flow rate, $\mathrm{cm}^{3} / \mathrm{S}$

L. Liquid mass flow rate per unit column cross-section, $\mathrm{kg} /\left(\mathrm{h} \cdot \mathrm{m}^{2}\right)$

in Mass flow rate, $\mathrm{kg} / \mathrm{h}$

NTU Number of a transfer unit, dimensionless

$\mathrm{P}$ Absolute vessel pressure, $\mathrm{Pa}$

q Rate of heat transfer, $W$

$\dot{q}^{-} \quad$ Rate of heat transfer per unit area, $W / m^{2}$

$\mathrm{R}$ Sphere radius, $\mathrm{cm}$

St Stanton number, dimensionless

t Liquid phase temperature, ${ }^{\circ} \mathrm{C}$

$t_{c}$ Condensate temperature, ${ }^{\circ} \mathrm{C}$

$T$ Vapor temperature, ${ }^{\circ} \mathrm{C}$

$T_{\text {sat }}$ Saturation temperature, ${ }^{\circ} \mathrm{C}$

$u$ Velocity of liquid phase, $\mathrm{cm} / \mathrm{s}$

v Superficial velocity of vapor (based on empty tower), $\mathrm{m} / \mathrm{s}$

$v$ Condenser volume, $\mathrm{m}^{3}$

$Z$ Bed height, $\mathrm{cm}$

a Thermal diffusivity, $\mathrm{m}^{2} / \mathrm{h}$

$\mu$ Viscosity, $\mathrm{Pa}, \mathrm{s}$

p Density, $\mathrm{kg} / \mathrm{m}^{3}$

$\sigma$ Surface tension, $\mathrm{N} / \mathrm{cm}$

I Liquid flow rate per unit wetted perimeter, $\mathrm{kg} /(\mathrm{h} \cdot \mathrm{m})$

B Angular coordinate, radians

$\theta$ Time, $s$

K Constant 
K Ratio of thermal conductivity of the coolant to that of the condensate, dimensionless

\section{Subscripts}

i. Either liquid-condensate or liquid-vapor interface as determined from context

1 Top of condenser

2 Bottom of condenser

$\checkmark$ Vapor phase

c Condensate

L Liquid phase

$x \quad$ Local value

- Initial value

Superscripts

* Based on wetted surface area 


\section{INTRODUCTION}

Direct contact heat transfer has a number of applications including water desalination, evaporative cooling and the condensation of steam in the electrical power industry. Direct contact heat exchange has also been proposed (1) as a method of utilizing geothermal brine by evaporating an immiscible secondary fluid which may be used to drive a low pressure turbine. Jacobs (2) has proposed the use of direct contact condensers in such binary power plants as a means of increasing the efficiency of electrical power production. It is this latter application of direct contact condensers that stimulated the present work.

In many applications the primary advantage of direct contact heat exchange is the elimination of scaling or fouling, this is especially important in utilizing geothermal brine in electric power generation. However, direct contact devices in general are of ten desirable because they are smaller and simpler in design than a conventional surface or tubular heat exchanger of equal capacity. This resuits in lower capital and ma intenance costs as well as a savings in floor space. Other advantages are the attainment of closer approach temperatures and, in the case of $D-C$ condensers, ease in eliminating noncondensibles from the working fluid.

The principal disadvantage of direct contact equipment is the possible loss of working fluid, but this problem can largely be overcome by proper separator design. Economically, the advantages of 
direct contact condensation far outweigh the disadvantages. Lackey (3) conducted a cost study of five different condensers, including packed bed and tubular, in which not only initial capital cost but operational and auxiliary equipment costs were considered. The packed tower system was by far the most attractive of the systems considered, having 23 percent lower overall cost than the surface condenser system and a 7 percent lower cost than the closest competing system (direct injection). Wilke and co-workers (4) also conducted a cost study of saline water conversion using direct contact equipment that compared favorably with conventional techniques.

There are three basic types of direct contact condensers:

1. Drop type condensers in which the vapor is the continuous media and condensation takes place on falling drops of the dispersed phase.

2. Bubble type condensers in which the vapor is injected into the continuous phase coolant as is done in an open feed water heater.

3. Film type condensers in which vapor condenses on a thin film of coolant.

Film type condensers are the subject of this study.

Since heat transfer is directly proportional to the interfacial area between two phases, one would expect the most efficient equipment would be that which gives a large interfacial area. This is achieved by filling a column with one or more of the commercially available bed materials such as Raschig rings, Pall rings, Berl saddles or Intalox saddles. 
In a packed tower such as this, the coolant is distributed over the packing at the top of the tower and filters down through the bed, coating it with a thin film on which condensation occurs. Since condensation is a constant temperature process, a counterflow configuration does not increase the heat transfer as it would be in a desuperheating application. A counterflow arrangement does, however, aid in the elimination of non-condensible gases. Therefore, packed beds are typically constructed with the gas phase entering at the tower base.

The present study is concerned with the performance characteristics of a film type condenser. Experimental data were obtained from a laboratory model using R-113 as the volatile fluid, and water as the coolant. R-113 was chosen because it is highly immiscible with water, and because its low boiling point makes it convenient for experimental study. The objectives of this project were to:

1. Experimentaliy determine the volumetric heat transfer coefficients for a specific direct contact situation using saturated vapor.

2. And, develop a correlation scheme for these data and apply it to other published data. 


\section{PREVIOUS WORK}

Although packed columns are widely used in industry as mass transfer devices, little has been published on their performance when used as heat exchangers. A large amount of absorption/desorption data is available for packed columns, however. Several investigators have used these data to estimate heat transfer coefficients by applying the mass and heat transfer analogy. This approach uses the penetration theory first proposed by Higbie (5) and yields the following relationship between the mass transfer coefficient $K_{L}$ and the heat transfer coefficient $h$ :

$$
\frac{h}{K_{L}}=\frac{C_{p} \rho(4 \alpha / \pi \theta)^{1 / 2}}{(4 D / \pi \theta)^{1 / 2}}=C_{p} \rho\left(\frac{\alpha}{D}\right)^{1 / 2}
$$

The derivation of this equation and other details of the penetration theory are presented in Section III, "Derivation of Basic Equations". By applying the definitions

$$
H T U_{H T}=L C p_{L} /(h a)
$$

and

$$
H T U_{M T}=L /\left(K_{L} a \rho\right)
$$

Equation 1 becomes

$$
\frac{\mathrm{HTU}_{\mathrm{HT}}}{\mathrm{HTU}_{\mathrm{MT}}}=(\mathrm{D} / \alpha)^{1 / 2}
$$


$K_{L}$ and $H T U_{M T}$ are obtained from published mass transfer data such as that of Sherwood and Holloway (6) for oxygen-water desorption. Harriott and Wiegandt (7) found that packed tower performance could be predicted fairly well using this approach. They obtained volumetric coefficients ranging from 93 to $280 \mathrm{~W} \cdot 10^{4} /\left(\mathrm{m}^{3} \cdot{ }^{\circ} \mathrm{C}\right)$ in a small packed condenser when the liquid rate varied from 3 to $20 \mathrm{~kg} \cdot 10^{4} /\left(\mathrm{h} \cdot \mathrm{m}^{2}\right)$. This corresponds to a volumetric heat transfer coefficient dependence on liquid rate to the 0.4 to 0.6 power. Coefficient values were not affected by gas rate variation. This was, of course, due to the fact that the vapor flow rate was equal to or exceeded the condensing capacity of the liquid.

The penetration theory approach seems to be satisfactory for systems in which mass transfer data are available. The problem is to determine $K_{L}$ and thus $H_{T} U_{M T}$ when data from a specific gas-liquid system are not available. Lackey (3) proposed an extension to the penetration theory that enables the data for a given system to be used in determining HTU ${ }_{M T}$ for a new system. By using an expression for the exposure time of the liquid interface in Equation 1, the relationship

$$
\frac{\mathrm{HTU}_{\mathrm{MT}}(1)}{\mathrm{HTU} U_{\mathrm{MT}(2)}}=\left(\frac{\mu_{1}}{\mu_{2}}\right)^{0.1555}\left(\frac{D_{2}}{D_{1}}\right)^{0.5}\left(\frac{\rho_{2}}{\rho_{1}}\right)^{0.333}\left(\frac{T_{2}}{T_{1}}\right)^{0.555-0.152 \log \mathrm{L}}
$$

was obtained. Values of HTU by Equation 5 for values of HTU $U_{M T(1)}$ obtained from gas-liquid data. After calculating HTU HT Equation 4, the bed height is determined in the usual manner, $Z=H T U_{H T} N_{T H}$ (see Equation 10). 
By combining Equations 4 and 5 and using Sherwood and Holloway's (5) correlation for $\mathrm{O}_{2}$-water desorption to eliminate HTU $\mathrm{MT}(1)$, Cheng (8) obtained

$$
\frac{\mathrm{HTU}_{\mathrm{HT}}}{\mathrm{HTU}}=\left(\frac{\mu_{\mathrm{HT}}}{\mu_{\mathrm{MT}}}\right)^{.55}\left(\frac{\mathrm{D}}{\alpha}\right)^{.05}\left(\frac{\rho_{\mathrm{MT}}}{\rho_{\mathrm{HT}}}\right)^{.33}\left(\frac{\sigma_{M T}}{\sigma_{H T}}\right)^{0.554-0.157 \log \mathrm{L}}
$$

This relationship was found to yield results approximately $15-20$ percent too large when compared to experimental data for steam con-

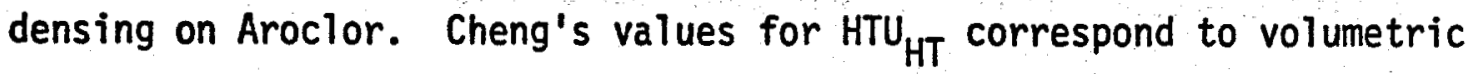
heat transfer coefficients of about $\left.11 \cdot 10^{4} \mathrm{~W} / \mathrm{m}^{3} \cdot \tau\right)$.

The penetration approach just discussed neglects the possibility of interfacial resistance and assumes all resistance is due to the liquid phase. This assumption is based on the fact that immediately after condensation occurs, the newly formed condensate is at the saturation temperature; hence, the boundary condition $T$ surface $=T_{\text {sat }}$. If a condensate film or other resistance is present on the surface of the liquid layer, the interfacial temperature will be different than $T_{\text {sat }}$. The difference depends on the thickness of the film and thus the latent heat of vaporization of the condensate. Consequently, the penetration model cannot be accurate as it does not consider vapor properties such as the latent heat of condensation.

Tamir and Rachmilev (9) and Maa and Hickman (10) have conducted studies indicating surface phenomena may account for as much as 50 percent of the total resistance in direct contact condensation. In Tamir's study, the interfacial resistance to condensation of a vapor 
on water passing over a sphere was assumed constant and was determined from theoretical curves for experimentally determined parameter values. Al though the constant resistance assumption was not exactly correct, the presence of appreciable interfacial resistance was established. In another study conducted by Tamir and Taite (11) the transfer to or from a vapor to a liquid film on an inclined plane was theoretically analyzed assuming a known interfacial resistance using both exact and approximate techniques. Al though the accuracy of integral methods was confirmed by the favorable comparison with the exact solution, this study did not provide a method of determining the interfacial resistance for a given liquid-vapor system. If the interfacial resistance for a given system is known, however, Tamir's results offer an easy method of estimating the overall heat transfer.

The only previous study attempting to theoretically determine the interfacial resistance to condensation of immiscible vapors is that of Sykes and Marchello (12). This study was concerned with the condensation of a mixture of organic and water vapor on a horizontal tube. It was assumed that the immiscible fluids separate instantaneously after condensation, and that the organic phase was under the water phase, 1.e. closest to the tube. Thus, two liquid resistances in series were assumed. The mean heat transfer for the twofilm model was obtained by following the procedure used by Nusselt to determine the heat transfer during the condensation of pure compounds on horizontal tubes. There was less than 5 percent difference in the total resistance when the resistance of the water-organic series was compared to that of the organic phase alone. When compared to 
eutectic heat transfer data, however, it was found that this model was inadequate. This led to the conclusion that the phenomena which occur during the condensation of eutectics are basically different from those occurring during pure component condensation. This conclusion is supported by the work of Bernhardt and co-workers (23) which shows that, during the condensation of a mixture of steam and organic vapor, a film of the organic phase forms on the solid surface, but the water phase forms droplets that float on the surface of the organic film.

Since the laminar two-film model predicted coefficients far above experimental results, the presence of another significant heat transfer resistance was speculated. It was assumed that this resistance was due, at least in part, to the lack of nucleation sites on the smooth wall-wetting phase. Although a theoretical model of this resistance was not attempted, a semi-theoretical data correlation based on nucleation theory was proposed and applied with good results.

Even though the system analyzed by Sykes and Marchello is that of a eutectic mixture rather than a pure vapor, the results are significant to the present study in that the possibility of significant nucleation resistance for systems of unlike chemistry is identified, and the comparatively small resistance of the water layer is revealed.

The significance of nucleation sites on the condensation of immiscible fluids is supported by the work of Maa and Hickman (10). It was found that the condensation of steam on a hydrophobic oil was increased with the addition of sensitizers to the coolant, which increased the number of nucleation sites. It should be observed that 
the increased number of points at which condensation may occur tends to cause a wetting of the liquid phase by the condensate, as opposed to the dropwise condensation that must occur when few nucleation sites are present. This is in contrast to the standard procedure of adding a non-wetting agent to a conventional heat exchanger to promote dropwise condensation, and, thus, increase heat transfer by preventing the build-up of the condensate film resistance. This seeming paradox is resolved by considering the relative thermal conductivities of the condensate and the cooling medium. In the conventional case, a metal having a high thermal conductivity is used to dissipate the latent heat of the vapor. In general, the metal has a higher conductivity than the condensate; and, therefore, it is desirable to eliminate the condensate film. When condensing water on oil, however, the condensate has a much higher conductivity than the coolant, so the film resistance becomes negligible compared to that of the coolant. It appears that it is more effective in this case for condensation to take place on the condensate film, thus eliminating nucleation resistance, and for conduction to the coolant to take place through the condensate-liquid interface rather than a vaporliquid interface.

The system under consideration in this study is one of a pure organic vapor condensing on an al ready present liquid coolant. If filmwise condensation occurs, the high thermal resistance of the condensate film will be of much greater importance than nucleation resistance, since the influence of nucleation phenomena is negligible for surfaces condensing their own vapors (10). Nucleation seems to 
be significant only when the vapor and the surface on which condensation occurs are of unlike chemistry. On the other hand, if dropwise condensation occurs, there is little resistance due to the condensate, but nucleation becomes increasingly important due to the unlike chemistry of the organic vapor and the water coolant. It is likely that a condition intermediate to these two extremes actually occurs. If this is true, the process could be influenced by the addition of sensitizers to the coolant to either promote or inhibit wetting. This is an area of future study that may prove beneficial.

In calculating HTU from Lackey's equation (Equation 5) and Cheng's equation (Equation 6), Rai and Pinder (13) noted that the variation in the viscosity factor over the range of temperatures studied was much greater than the variation in the remaining factors. Concluding from this that the process was largely dependent on the liquid phase viscosity, they derived the following equations by fitting curves to data they obtained

$$
\mathrm{HTU}_{H T}=\left(0.0276+1.24 \times 10^{-5} L\right)\left(\mu_{L}\right)^{1.16}
$$

and

$$
H T U_{H T}=\left(0.0535+8.90 \times 10^{-6} L\right)\left(\mu_{L}\right)^{1.10}
$$

Equations 7 and 8 apply to steam condensing on Aroclor 1242 and 1248 respectively, and are only valid in the laminar flow regime. Since the flow configuration is co-current in a bed of Raschig rings, as compared to the counter-flow arrangement of Wilke (4) and Lackey (3), 
the disagreement in the viscosity exponent is not surprising. It should be noted that the linear dependence of the heat transfer on the liquid flow rate is in contrast to the results of Harriott and Wiegandt (7) discussed earlier.

The strong dependence of HTU on liquid phase viscosity was noted by Harriott and Wiegandt (7) while comparing the experimental results of Wilke and co-workers (4) for steam condensing on Aroclor with values predicted using oxygen-water desorption data and the penetration theory discussed earlier. For liquid rates in the range of 10 to $15 \mathrm{~kg} \cdot 10^{4}$ / $\left(\mathrm{h} \cdot \mathrm{m}^{2}\right)$ Wilke obtained a coefficient of about $11 \cdot 10^{4} \mathrm{~W} /\left(\mathrm{m}^{3} \cdot{ }^{\circ} \mathrm{C}\right)$. The large discrepancy was attributed to the increased residence time of the highly viscous Arocior.

Hu (14) proposed a design technique using Sherwood and Holloway's correlation

$$
\mathrm{HTU}_{\mathrm{MT}}=\frac{1}{170}\left(\frac{L}{\mu}\right)^{0.23}\left(\frac{\mu}{\rho_{L} D_{L}}\right)^{0.5}
$$

for oxygen-water desorption. The diffusivity was found from Wilke's (15) equation

$$
D_{L}=\frac{4.0 \times 10^{-7} T_{L}}{\mu\left(V_{S}^{1 / 3}-K_{1}\right)}
$$

where

$$
\begin{aligned}
& T_{L}=\text { absolute temperature of liquid, oR. } \\
& \mu=\text { viscosity of the solution, } 1 \mathrm{~b} / \mathrm{hr} \mathrm{ft} . \\
& K_{1}=2.0 \text { for solution in water. } \\
& V_{s}=\text { molecular volume of solute, calculated from atomic volume. }
\end{aligned}
$$


The value of NTU was calculated from

$$
N T U_{H T}=\frac{h a V}{L(L e) C_{p_{V}}}
$$

where

$$
\frac{H a V}{L}=\frac{\left(t_{2}-t_{1}\right)}{L M T D}=L e={\frac{k v}{\rho_{v}{ }^{D} C_{p_{v}}}}^{2 / 3}
$$

The bed height is again determined as the product of HTU and NTU. This procedure, however, is of questionable validity. Why the bed height for condensation should be determined as the product of an NTU for heat transfer and an HTU for mass transfer is not explained. Also, as Lackey (3) pointed out, determining bed height as the product of an NTU based on vapor properties and an HTU based on liquid properties is incorrect. This procedure was not supported by experimental verification. Hu does, however, present a method that may be of value in sizing a separator when immiscible fluids are used.

As either the liquid or vapor rate is increased in a packed tower of given diameter, the liquid hold-up is increased, and, consequently, the area for vapor flow is reduced. A definite point is finally reached at which the pressure rises sharply and the vapor violently bubbles up through the liquid phase. This condition is known as flooding. In designing a packed tower, therefore, not onnly the height but the bed diameter must be determined. An experimental correlation of

$$
\frac{L}{G}=\left(\frac{\rho_{v}}{\rho_{L}}\right)^{1 / 2} \text { vs } \frac{v^{2}}{g} \frac{\mathrm{a}}{F^{3}} \frac{\rho_{v}}{\rho_{L}} \mu^{0.2}
$$


has been developed by Sherwood and Shipley (16) from which compatible vapor and liquid rates may be determined once the condenser heat load is known. By calculating the maximum allowable vapor velocity for a given liquid flow rate from this relationship, the minimum bed diameter required to avoid flooding may be found. Eckert (17) has presented a similar procedure for determining the appropriate diameter for a packed column.

Other studies of direct contact heat transfer in packed towers include that of 0lander (18), in which an analysis free of all unnecessary simplifying assumptions is presented. A point-by-point analysis of the bed conditions as a function of height is made by solving the simultaneous differential equations describing the process. Although his study is limtied to direct contact coolers, the procedure could possibly be extended to condensers as well. Bras (19) and Fair (20) also present techniques for the design of $D-C$ coolers that are of interest in the study of packed tower condensers. 


\section{DERIVATION OF BASIC EQUATIONS}

This section consists of three parts. Part A contains the elementary packed bed theory leading to the definition of HTU and NTU. In Part B, the penetration theory first proposed by Higbie (5) is presented, and how it has been used to relate heat and mass transfer is shown. Penetration theory is then applied in Part $C$ to the condensation of an immiscible vapor on a liquid film to obtain an expression for the volumetric heat transfer coefficient in a condenser packed with spheres.

\section{A. Definition of HTU, NTU and St}

Packed bed heat transfer is often presented in terms of the height of a transfer unit, HTU, which has been defined as a result of integrating the heat balance equation for a differential height of packing as follows:

$$
\begin{aligned}
d \dot{q}= & L A C_{p} d t=h a A(T-t) d z \\
& \int_{0}^{z} d z=\int_{t_{2}}^{t_{1}} \frac{L C_{p}}{h a} \frac{d t}{(T-t)} . \\
Z & =\left[\frac{L C_{p}}{h a}\right]-\ln \left[\left(T-t_{2}\right) /\left(T-t_{1}\right)\right]
\end{aligned}
$$

The factor $\left[L C_{p} / h a\right]$ in Equation 9 is the "Height of a Transfer Unit", and the logarithmic factor has been termed the "Number of Transfer Units", or NTU. Thus, 
15

$Z=H T U \cdot N T U$

(10)

Since the exit temperature of the liquid-condensate mixture from

a direct contact condenser can be calculated from a simple heat

balance, the NTU is easily determined. The problem is to determine

what factors influence the value of HTU; or, alternately, the volumeEric heat transfer coefficient ha.

The nondimensional heat transfer coefficient used in this study is the Stanton number, defined as

$$
\begin{aligned}
S t & =\frac{\hbar}{p_{v} C_{p_{v}}} \\
& =\frac{\hbar a}{(\dot{m} / A) C_{p_{v}}}
\end{aligned}
$$

where $\overline{h a}$ is the volumetric heat transfer coefficient. A modified Stanton number based on the effective whetted area instead of the total packing area is also used. In this case

$$
S t^{*}=\frac{\hbar a}{\rho_{v} C_{p_{v}} v\left(a_{w} / V\right)}
$$

The HTU is related to the Stanton number by

$$
\text { UTU }=\frac{C}{\text { St } a}
$$

where

$$
c=\frac{\dot{m}_{L} c_{p_{L}}}{\dot{m}_{v} c_{p_{V}}}
$$


B. Penetration Theory

The penetration theory used to estimate HTU for heat transfer from mass transfer data assumes that heat is absorbed by an element of area on the surface of the $f i l m$, and that the surface attains a temperature equal to that of the continuous phase during the first instant of exposure, i.e. the interfacial resistance is zero and the liquid phase resistance is controlling. This may or may not be a reasonable approximation depending upon the resistance of the condensate film growing upon the liquid coolant. The liquid behind the interface is assumed to be an infinitely deep stagnant layer during the time in which the element travels from the top of the packing element to the bottom. The latter is a reasonable assumption for short periods of exposure. Axial conduction is neglected. Mathematically the problem is expressed as

$$
\begin{array}{lll}
\frac{\partial t}{\partial \theta}=\alpha \frac{\partial^{2} t}{\partial y^{2}} & \\
t=t_{0}, & y \geq 0 & \theta=0 \\
t=t_{i}, & y=0 & \theta>0 \\
t-t_{0} & y=\infty & \theta \geq 0
\end{array}
$$

Solving by Laplace transformation yields

$$
\frac{t-t_{i}}{t_{0}-t_{i}}=\operatorname{erf} \sqrt{\frac{y^{2}}{4 a \theta}}
$$

The instantaneous rate of transfer per unit area is

$$
\dot{q}=-\left.k \frac{\partial \gamma^{t}-t_{i}}{\partial y}\right|_{y=0}=-k\left(t_{0}-t_{i}\right) / \sqrt{\pi \alpha \theta}
$$


The average heat transfer during time $\theta$ is

$$
\dot{q}_{A V G}=\frac{1}{\theta} \int \dot{q}^{-} d \theta=-2 k\left(t_{0}-t_{i}\right) / \sqrt{\pi \alpha \theta}
$$

By applying the definition of $\bar{h}$, we have

$$
\dot{q}_{A V G}=-2 p C_{p}\left(t_{0}-t_{i}\right) \sqrt{\frac{\alpha}{\pi \theta}}=h\left(t_{i}-t_{0}\right)
$$

or

$$
\bar{h}=\rho c_{p} \sqrt{\frac{4 \alpha}{\pi \theta}}
$$

By solving the mass transfer equation

$$
\frac{\partial c}{\partial \theta}=D \frac{\partial^{2} c}{\partial y^{2}}
$$

In a similar manner, one may obtain

$$
\bar{K}_{L}=\sqrt{\frac{4 D}{\pi \theta}}
$$

The ratio of the two coefficients is then

$$
\bar{h} / \bar{K}_{L}=\rho C_{p} \sqrt{\alpha / D}
$$

$$
\begin{aligned}
& \text { Since } H U_{H T}=L C_{p} / \text { ha and } H T U_{M T}=L /\left(K_{L} \text { a o), Equation } 14\right. \text { becomes } \\
& \frac{H T U_{H T}}{H T U_{M T}}=\sqrt{D / a}
\end{aligned}
$$

which is Equation 4 of the introduction.

The time required for the surface of a liquid film to travel the distance $Z$ on a vertical plate is found from boundary layer theory to be 


$$
\theta=\frac{z}{u_{i}} \quad \text { where } u_{i}=\left(\frac{g g \Gamma^{2}}{8 \mu \rho}\right)^{1 / 3}
$$

By substituting this expression into Equation 13, Lackey (3) obtained Equation 5 of the introduction, which enables one to estimate the HTU $_{\text {MT }}$ for a given system from the mass transfer data of another system.

\section{Theoretical Approach}

It has been shown how penetration theory is used to relate mass and heat transfer, and how this relationship is used to estimate heat transfer coefficients from mass transfer data. In this section, the penetration theory presented in Section $B$ is applied directly to condensation in a bed packed with spheres. It should be recalled that this approach neglects the influence of vapor properties and the resistance of the condensate layer at the interface. It is realized by the author that these assumptions are probably not justified, but the analysis is undertaken for purposes of comparison in order to test the validity of the penetration theory as applied to condensation processes.

The time required for the surface of a liquid film to flow over a small sphere may be estimated by the following relationship

$$
\theta=\left(\frac{32 \nu \pi^{i}}{9 g}\right)^{1 / 3} e^{-2 / 3} \quad R^{5 / 3} \int_{0}^{\pi}(\sin \alpha)^{1 / 3} d \alpha
$$


where the value of the integral as determined by numerical means is 2.58. In this equation, which was derived by Lynn and co-workers (24) from boundary layer theory, $R$ is the radius of the sphere and is the volumetric flow rate of the liquid phase over the sphere. A rough approximation to the total residence time of the liquid phase in a column packed with spheres is

$$
\theta_{\text {Tot }}=\theta \frac{z}{d}
$$

By combining Equations 12, 16 and 17, and by multiplying the area heat transfer coefficient by the effective wetted area of packing per unit volume, the volumetric heat transfer coefficient becomes

$$
h_{a}=\frac{a_{w} p C_{p}}{v} \sqrt{\frac{4 \alpha d}{2.58 z\left(\frac{32 v \pi^{5}}{9 g}\right)^{1 / 3} l^{-2 / 3} R^{5 / 3}}}
$$

Equation 18, if the assumption of the simplified penetration theory were applicable, could thus be used to obtain the average volumetric heat transfer coefficient in the packed bed. Comparison with the experimental data is given in Chapter $V$. 


\section{EXPERIMENTAL APPARATUS AND PROCEDURE}

\section{A. Test Apparatus}

A description of the experimental apparatus and test procedure used in obtaining data for the direct contact condensation of $R-113$ vapor on water in a packed bed is given in this section.

\section{System}

A schematic of the system is shown in Figure 1. Water was pumped from a reservoir through the system by a 559 watt pump. Flow was regulated by means of a system by-pass that returned a portion of the water leaving the pump to the reservoir. Water not returned to the reservoir through the by-pass, either proceeded directly to a temperature control mixing valve, or passed through a series of two small, two-pass shell-and-tube heat exchangers to be cooled before reaching the mixing valve.

The mixing valve was a Calumet Manufacturing Co. temperature sensing valve capable of automatically mixing the necessary proportions of hot and cold water required to maintain the discharged mixture at the constant temperature specified by the valve setting. Water then passed through a rotameter with a range from 0 to 21 $\mathrm{k}_{\mathrm{g}} /$ min that was calibrated to \pm .1 percent of the full scale reading. The water then entered the top of the condenser and filtered through the column packing to the hot-well. Condensed R-113 was also present in the hot-well and this condensate-water mixture discharged from the 


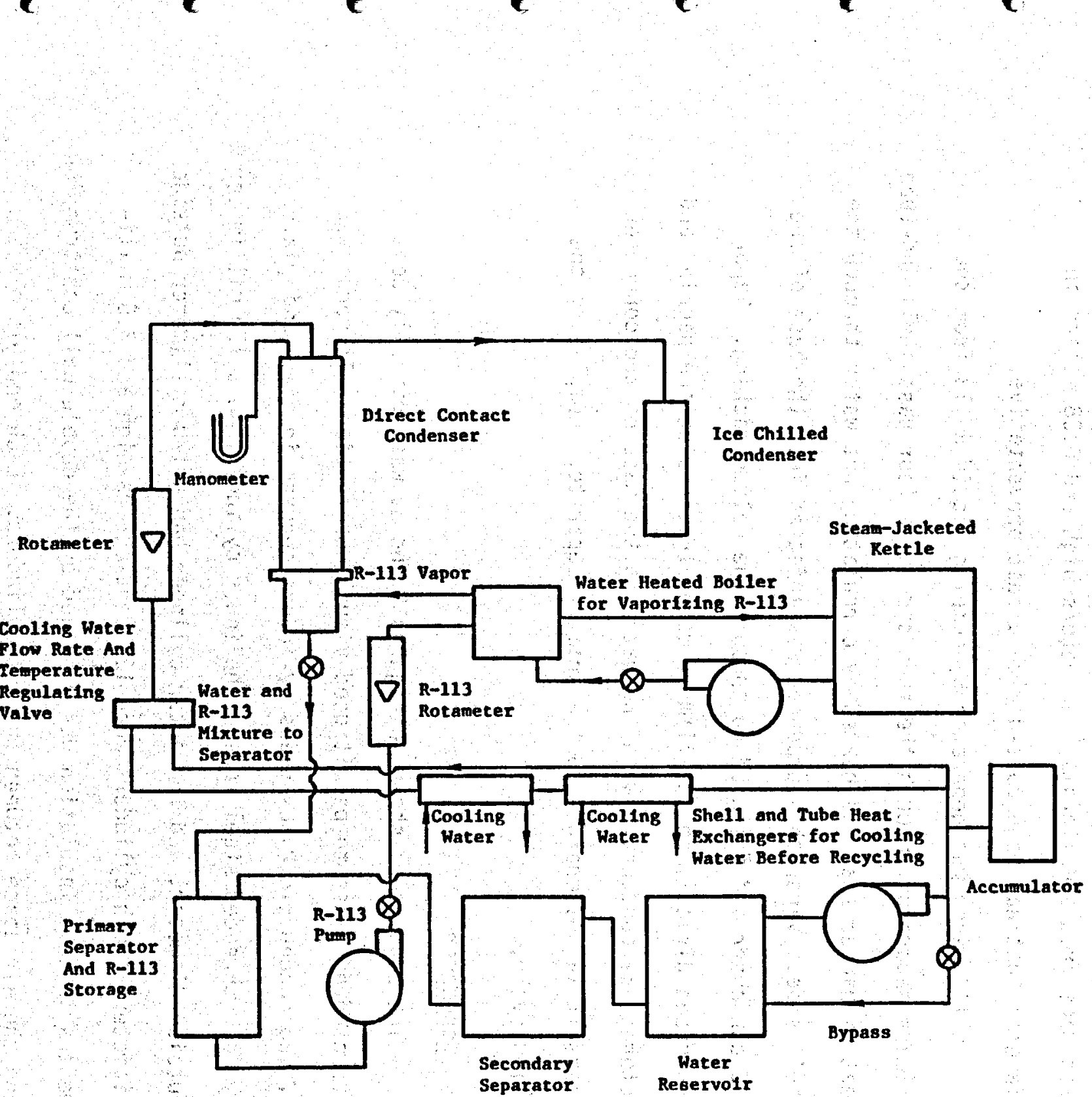

Figure 1. Schematic of System for Direct Contact Condensation of R-113 
vessel to the primary separator. After leaving the primary separator, the water passed through a secondary separator before returning to the water reservoir. The secondary separator and the reservoir were each made from steel drums 0.53 meters high and 0.38 meters in diameter that had been coated with a rust preventative.

$R-113$ vapor was generated by pumping liquid $R-113$ from the primary separator through the tube side of a four pass shell-and-tube heat exchanger that was heated by circulating hot water through the shell side. Vapor thus produced was injected into the base of the $D-C$ condenser and filtered up through the column packing. Vapor condensed directly on the film of water that coated the packing and returned as condensate with the water to the base of the condenser where it was discharged to the primary separator, completing the R-113 cycle.

\section{Condenser}

The condenser, shown in Figures 2 and 3 , was primarily constructed of glass to permit good visual observation. It consisted of two concentric Pyrex glass cylinders secured in steel end plates by four threaded steel rods. The inner cylinder had a 150 millimeter outside diameter, and the outer cylinder had a 170 millimeter outside diameter. Both cylinders were 122 centimeters high and 3.5 millimeters thick. Insulation was provided by the double wall construction and the air space between the two cylinders. Each end plate was made of $12.7 \mathrm{~mm}$ thick mild steel and had two concentric grooves on one side to accommodate 0 -ring seals. 


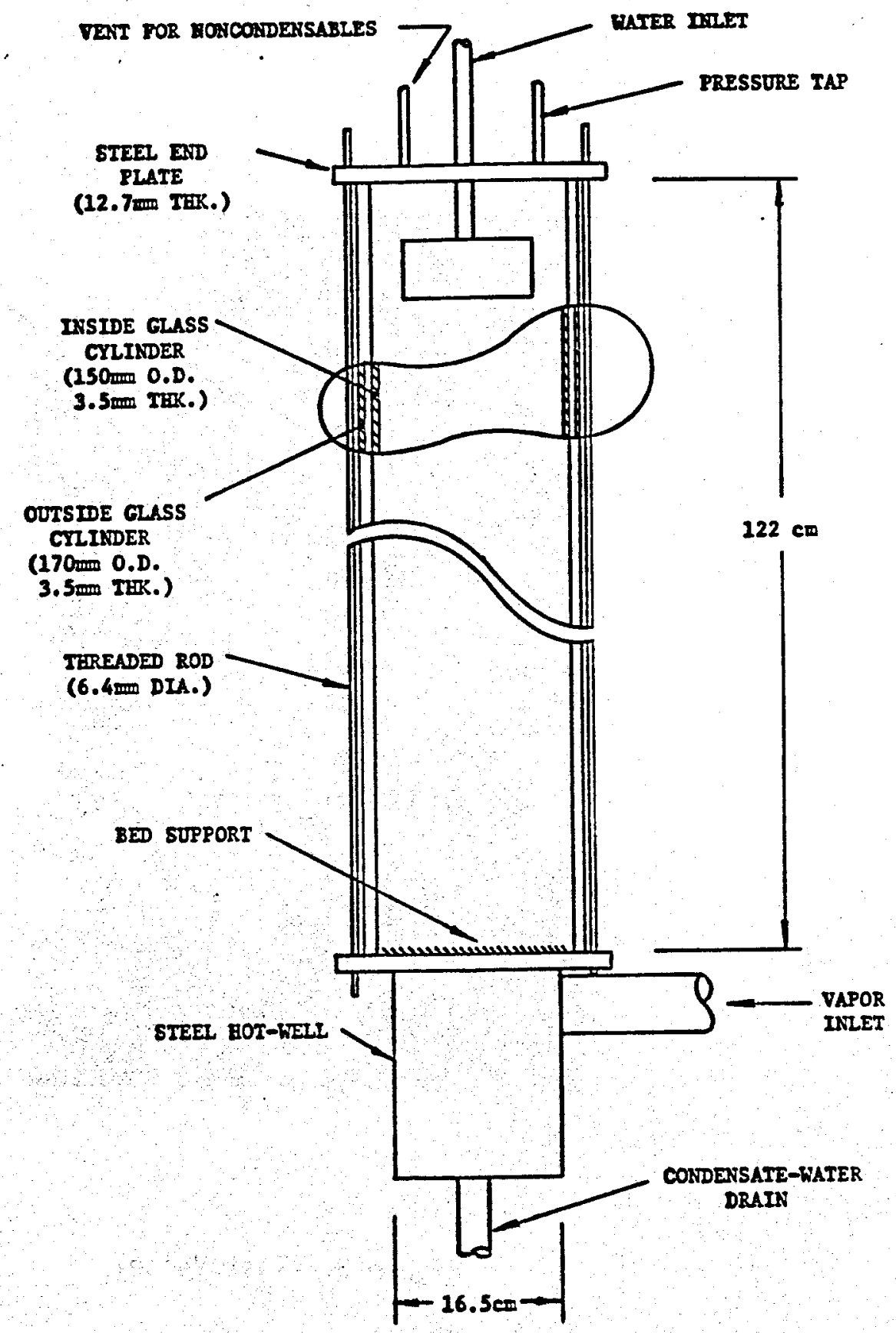

Figure 2. Schematic of Test Vesse] 


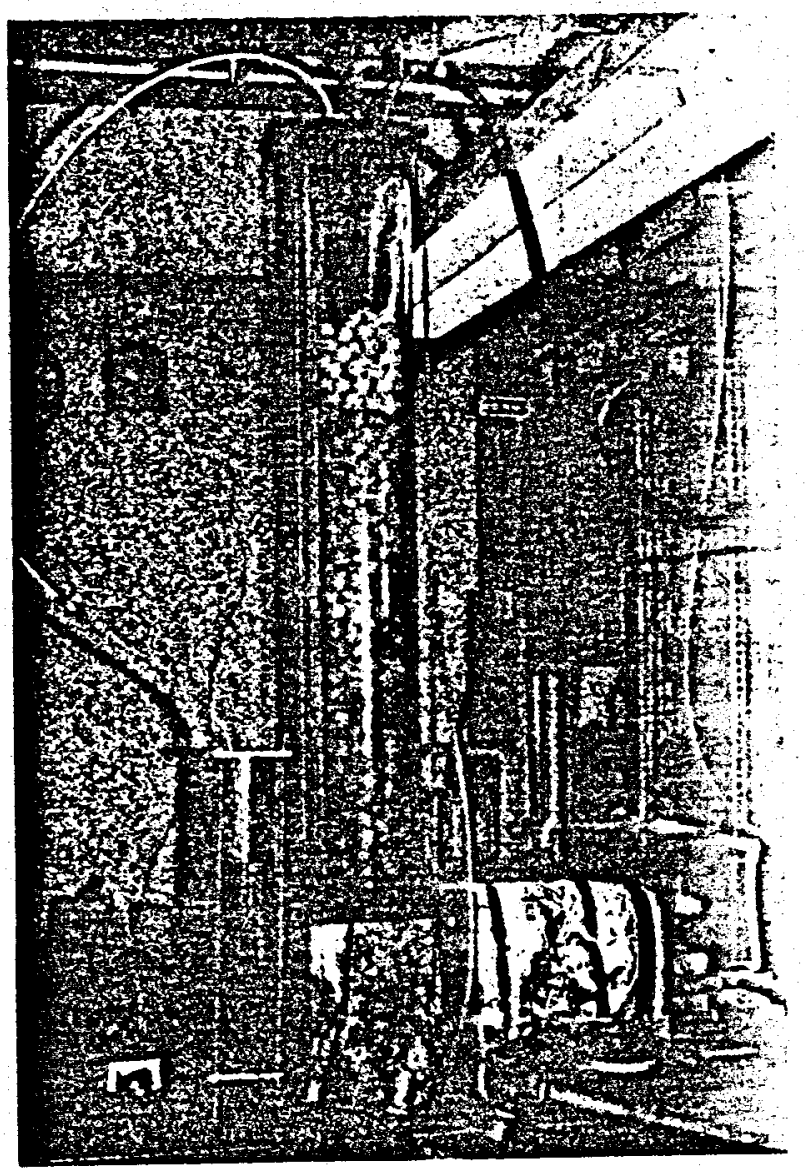

Figure 3. Test Vesse1 
A steel hot-well was welded to the bottom end plate that had an 88.9 millimeter diameter conduit attached to its side, to allow entry of the vapor. Epoxy resin was used inside the hot-well to prevent rust. A 25.4 milli imeter diameter pipe connected to the hot-well provided drainage to the primary separator. This pipe had an 80 millimeter radius " $U$ " at the condenser end to prevent the passage of vapor.

The top end plate had a removable lid, also made of steel, which allowed for the addition and removal of packing. A 6 millimeter inside diameter tube connected a port in the lid to the bottom of a 38.1 centimeter deep column of water. This vent permitted the removal of non-condensables from the vessel and acted as a pressure relieve valve. The vent also allowed vapor to escape when vessel operating conditions were not adequate for complete condensation.

The liquid-vapor saturation point was determined from the vessel pressure. This was measured with a mercury manometer that indicated the pressure difference between the top of the vessel and ambient. Initially a water manometer was used to measure the pressure drop through the column packing. However, it was found that the pressure difference was too small to be measured accurately with this device; and, thus, was too small to be of significance in determining the saturation point. Therefore, the pressure drop through the column was ignored.

Water entered the vessel through a 12.7 millimeter diameter copper tube penetrating the vessel lid. This tube supplied the cooling water to the spray manifold. The depth of this tube into 
the vessel was adjustable to enable the spray manifold to be located 25 millimeters above the packing for any packing height.

Support for the packing was provided by a rigid wire grid that rested on the top face of the bottom end plate inside the inner glass cylinder.

Temperatures were monitored with copper-constantan thermocouples calibrated to $\pm 0.1^{\circ} \mathrm{C}$. Thermocouples were located at the vapor inlet, the water-condensate exit, and in the water inlet manifold. Ten other thermocouples were embedded in the column packing at 10.2 centimeter intervals from the bed support to a height of 92 centimeters.

\section{Primary Separator}

The primary separator is shown in Figures 4 and 5 . The separator, which also functioned as a $R-113$ storage reservoir, was similar in construction to the condenser in that four threaded steel rods held $12.7 \mathrm{~mm}$ thick end plates to a $150 \mathrm{~mm}$ diameter Pyrex glass cylinder. A $25 \mathrm{~mm}$ diameter pipe through the top plate permitted entry of the condensate-water mixture. This pipe extended down from the top plate $35 \mathrm{~cm}$ and attached to a $90^{\circ}$ elbow. Since liquid $\mathrm{R}-113$ is approximately 50 percent heavier than water, it readily settled to the bottom of the cylinder where it was pumped from the separator through an exit in the bottom plate. Water rose to the top of the cylinder and was forced out of the separator through a $25 \mathrm{~mm}$ diameter tube to the secondary separator.

Since the residence time in the primary separator apparently was not great enough, a considerable amount of $R-113$ departed with 


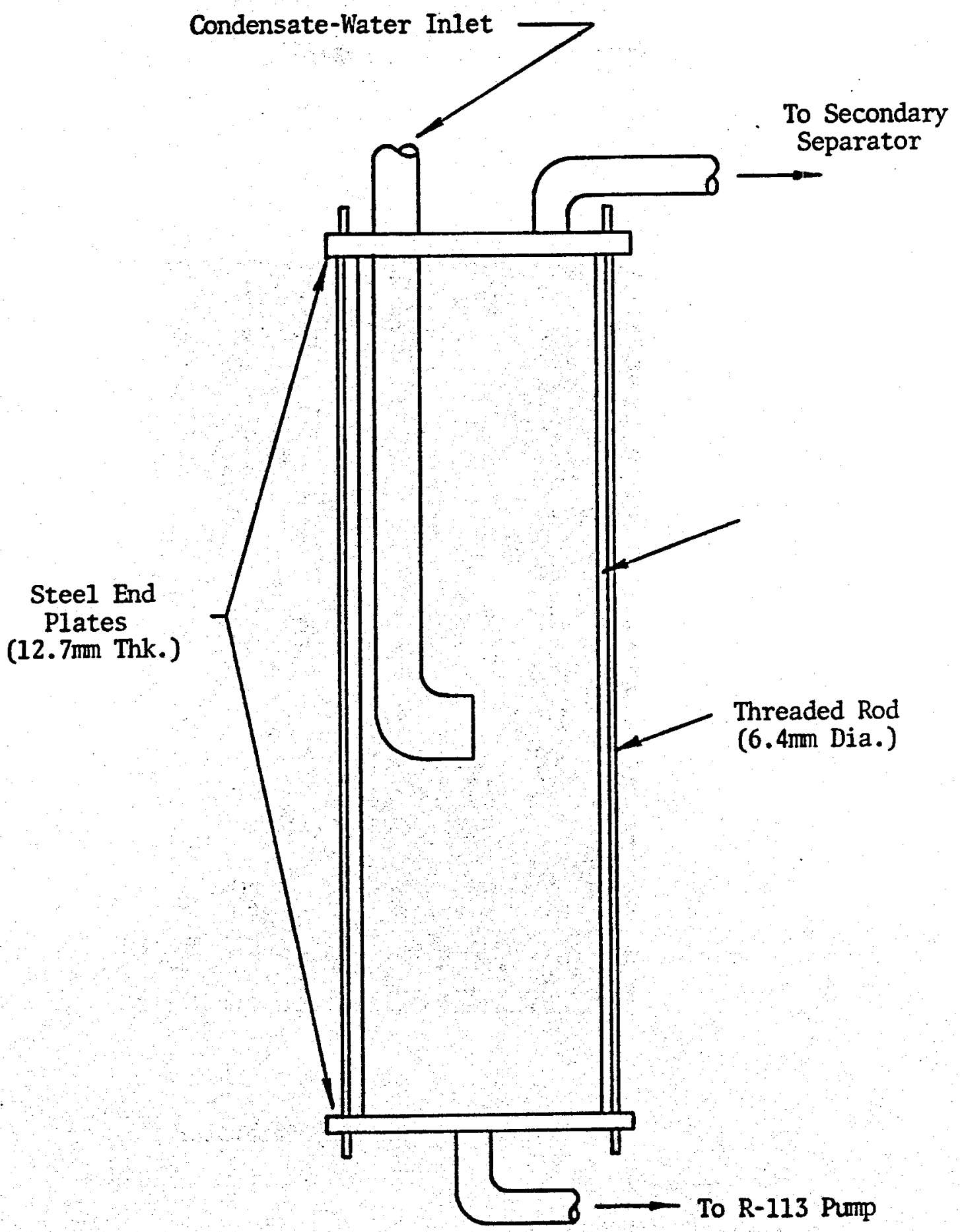

Figure 4. Schematic of Primary Separator 


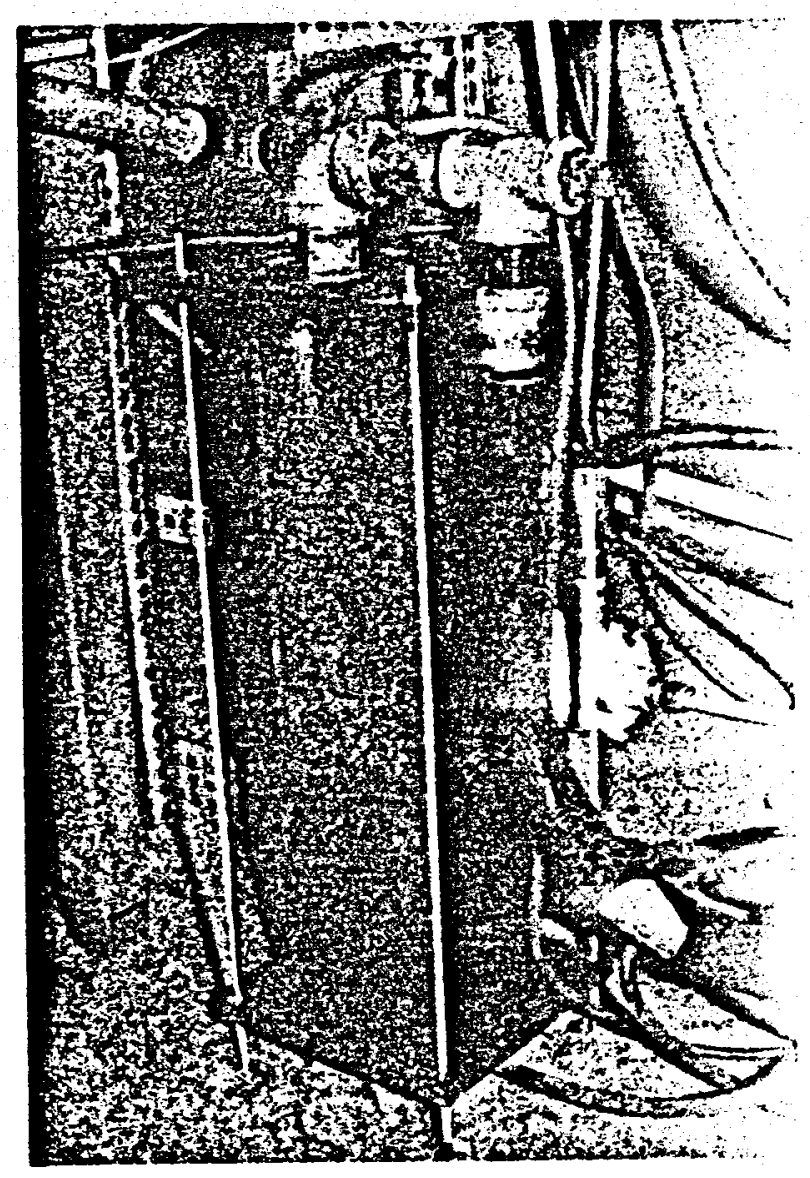

Figure 5. Primary Separator 
the water. This necessitated the construction of the secondary separator. A hand pump was used to pump R-113 from the secondary separator back to the primary separator at approximately 20 minute intervals.

\section{Water Inlet Manifold}

A water iniet manifold made of brass was used as the liquid distributor. Figure 6 shows the details of construction. The seven full cone nozzles provided approximately uniform liquid distribution when positioned $25 \mathrm{~mm}$ above the packing. The droplet size was not considered important since the flow was evened out after passing over the first several packing layers. Inlet water temperature was measured by a copper-constantan thermocouple located in the manifold. The thermocouple wires ran up through the water inlet tube to which the manifold was attached, and exited the tube at a location above the vessel lid. The spray manifold, thermocouple, and lid assembly is shown in Figure 7. An interior view of the spray manifold is shown in Figure 8.

\section{B. Experimental Procedure}

The start up procedure for the experimental apparatus consisted of the following steps:

1. First the vent provided for the elimination of noncondensables was opened to prevent over pressurization of the vessel when the coolant was circulated.

2. The water was now circulated at the desired flow rate and the drain valve was adjusted until the water height in the hot-well remained constant. 


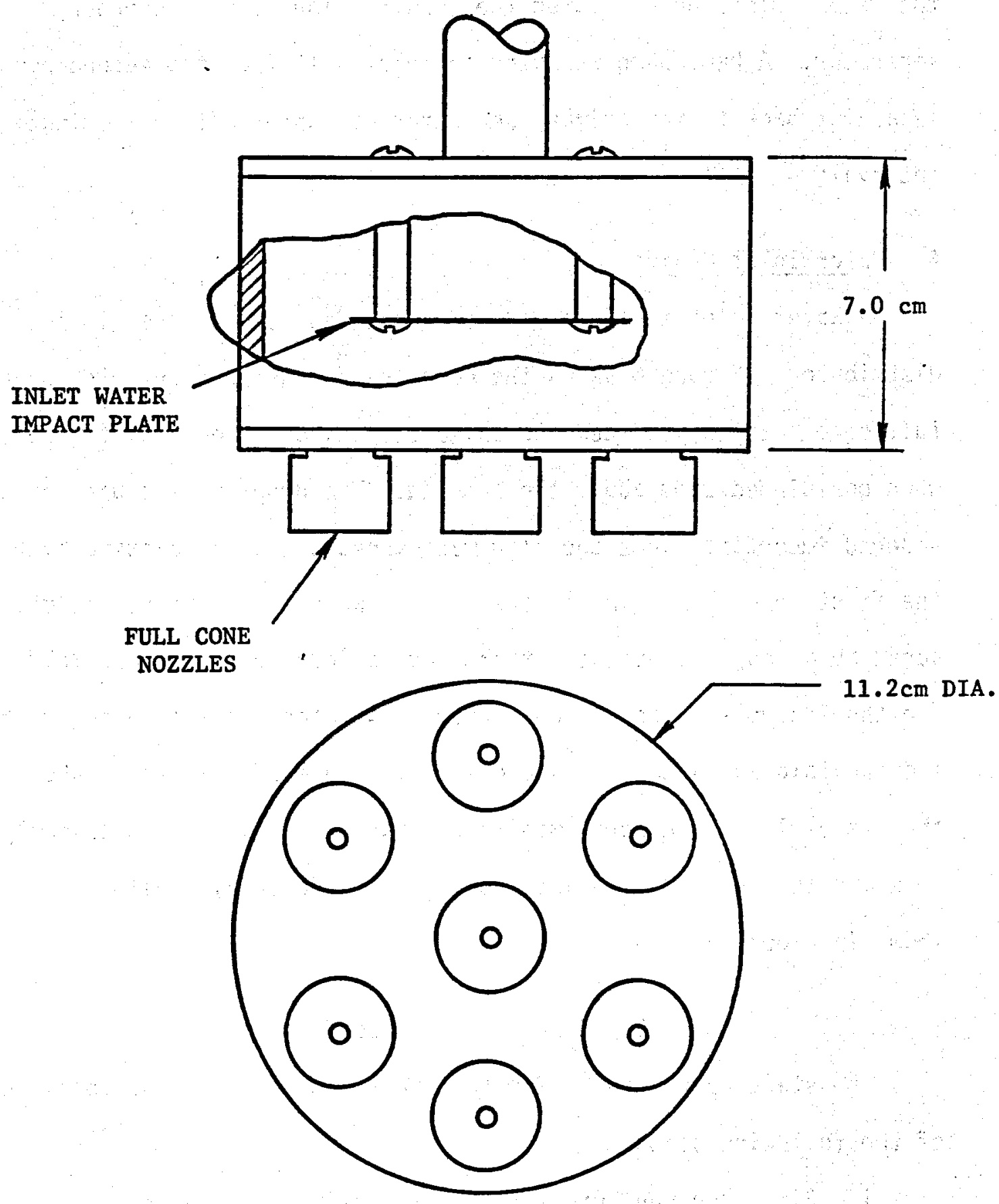

Figure 6. Construction Details of Water Spray Manifold 


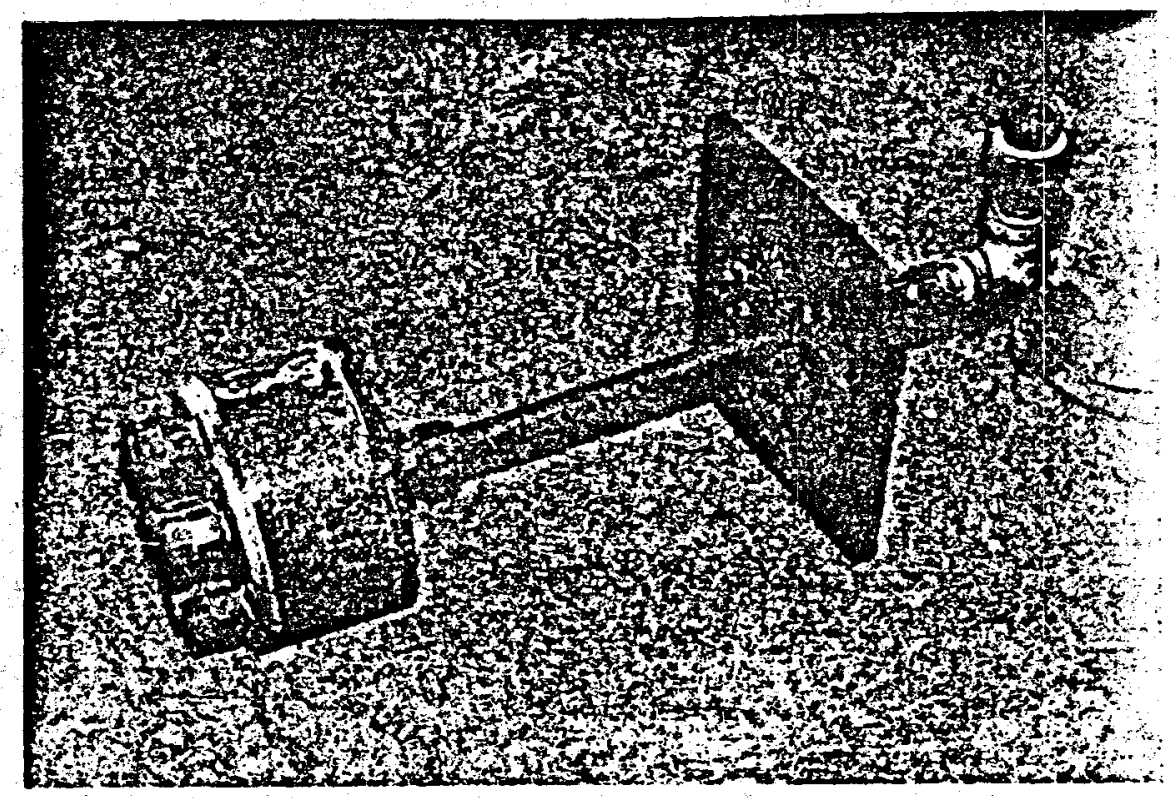

Figure 7. Spray Manifold and Water Inlet Assembly

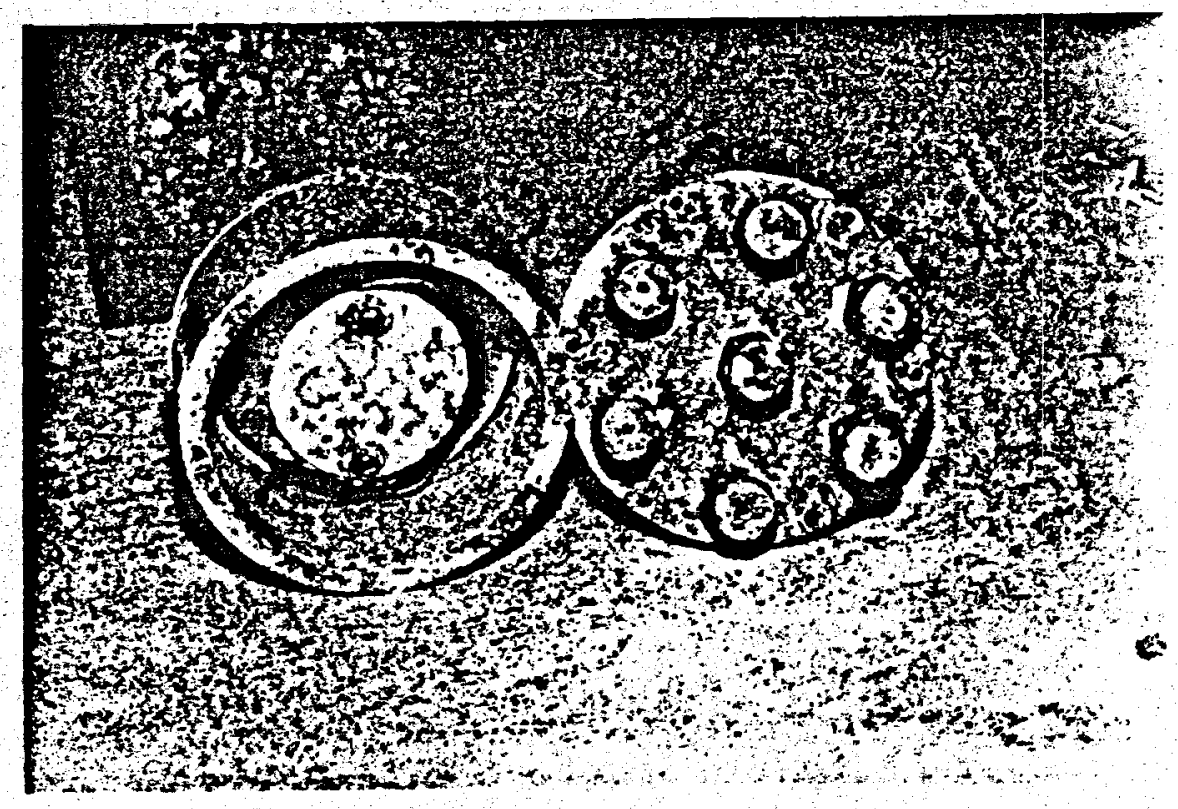

Figure 8. Spray Manifold Interior 
3. Freon vapor was generated by circulating hot water through the boiler.

4. After the coolant was heated sufficiently, water was circulated through the two sma11-shell-and-tube heat exchangers to prevent the coolant from overheating.

5. Both warm and cool water were now available to the mixing valve, which was set to the desired cooling water temperature for the experiment.

6. The R-113 flow rate was increased in steps, and the system was allowed to stabilize at each flow setting. Stabilization took approximately 45 minutes.

7. When the R-113 flow rate was increased to the point that complete condensation within the bed was not possible, the rate was reduced to a setting slightly greater than the previous flow setting for which complete condensation was possible. This procedure was followed until the maximum $R-113$ flow rate was found that would also permit complete condensation to occur within the bed.

8. After the flow setting described in step seven was obtained, all temperature and pressure measurements were made.

9. To obtain the next set of data, the water flow rate and/ or temperature was changed and the procedure was repeated beginning with Step 6 . 
V. DISCUSSION OF RESULTS

This discussion consists of four parts. Part A presents the method of data correlation and the resulting relationship. In Part $B$ some comments and observations on the correlation are made. A comparison with other experimental work is made in Part C. The result of the penetration theory analysis is compared to experimental values in Part $D$.

A. Correlation Equation

Data were obtained for $R-113$ vapor condensing on water using both $3.2 \mathrm{~cm}(1.25 \mathrm{inch})$ diameter ceramic sphere packing and $2.5 \mathrm{~cm}$ (1.0 inch) ceramic Berl saddles. These data, along with data reported by Chang (8) for steam condensing on Aroclor using $2.5 \mathrm{~cm}$ Raschig rings, were reduced and correlated to yield a non-dimensional relationship for the condensation heat transfer in a packed bed.

From the dimensional analysis, the physical quantities considered important in the direct contact condensation of an immiscible vapor on a liquid coolant are: $\dot{m}_{L}, \dot{m}_{v}, \rho_{L}, \rho_{v}, c_{p_{L}}, c_{p_{v}}, h_{f}, k_{L}, k_{C}, h$, $Z$ and the bed diameter. The grouping of these parameters chosen as the non-dimensional heat transfer coefficient for the purpose of data correlation is the Stanton number, which was defined in Chapter III. Details of the procedure that was followed in obtaining a relationship between the Stanton number and other important dimensiontess groupings of the above mentioned parameters is given below. Appendix 
I describes the method of data reduction, and Appendix II contains all raw and reduced data obtained for this study.

1. Stanton Number Dependence on Jakob Number

Jacobs (21) has shown analytically that the dimensionless grouping of parameters that characterizes the vapor properties and the operating temperatures in direct contact condensation is the Jakob number, which is defined as

$$
J a=\frac{h_{f_{g}}}{c_{p_{v}}\left(T_{\text {sat }}-t_{a v g}\right)}
$$

Stanton number dependence on Jakob number was determined from Figures $9,10,11$ and 12 , where St versus $\mathrm{Ja}$ is plotted separately for each system considered in this study, and the data are grouped with respect to bed height. Grouping according to hourly heat capacity ratio was not needed. The dependence, as determined by the slope of the best fit line for each height grouping is $\mathrm{Ja}^{1.0}$, i.e. Stanton number is directly proportional to the Jakob number.

\section{Stanton Number Dependence on Heat Capacity Ratio}

The influence of the relative mass flow rate on the Stanton number is taken into account by correlating the data with respect to the hourly heat capacity ratio, defined as

$$
\dot{c}=\frac{\dot{m}_{L} c_{p_{L}}}{\dot{m}_{v} c_{p_{v}}}
$$





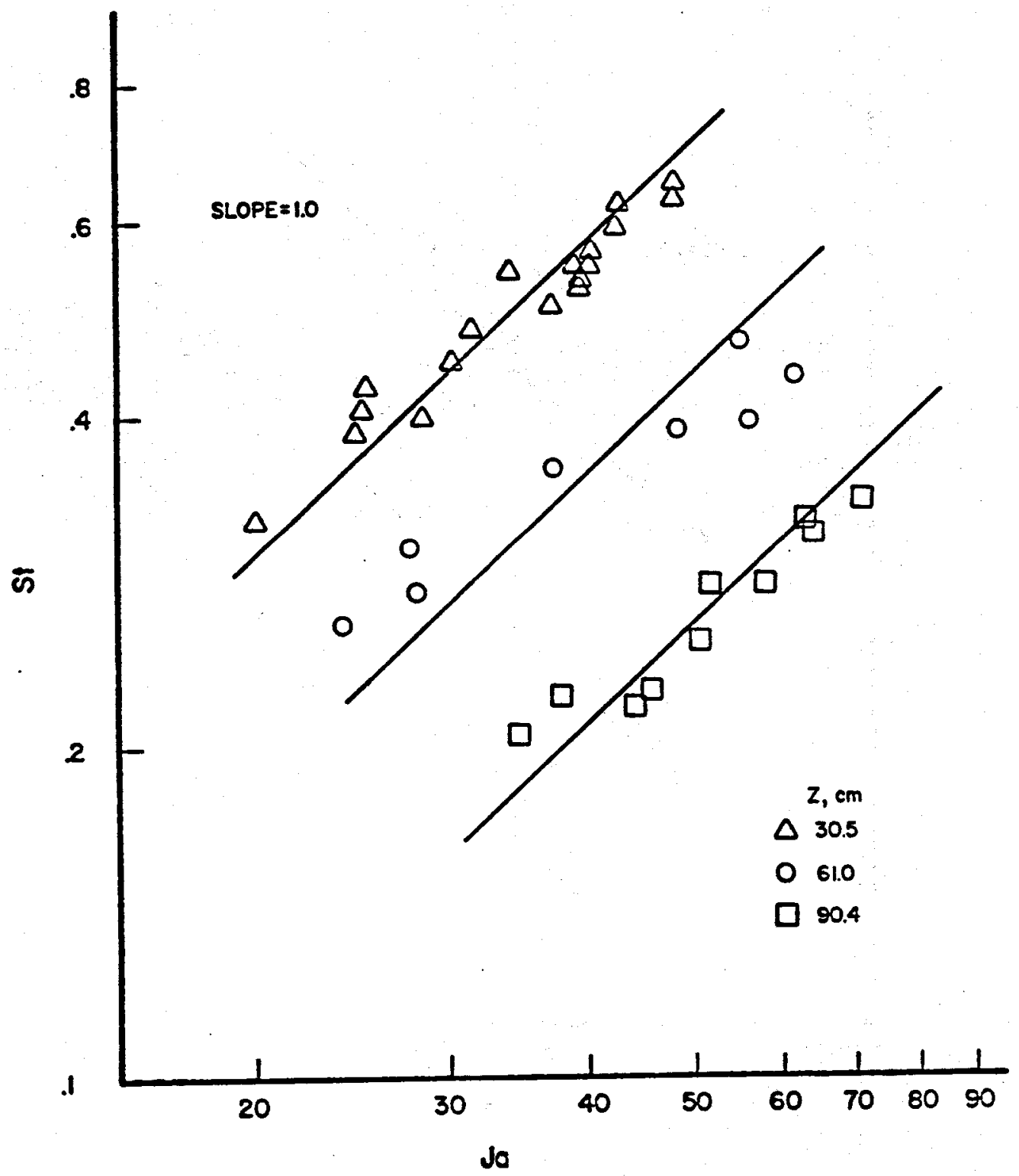

Figure 10. Effect of Ja on St for R-113 - water System Using $2.5 \mathrm{~cm}$ Berl Saddle Packing 


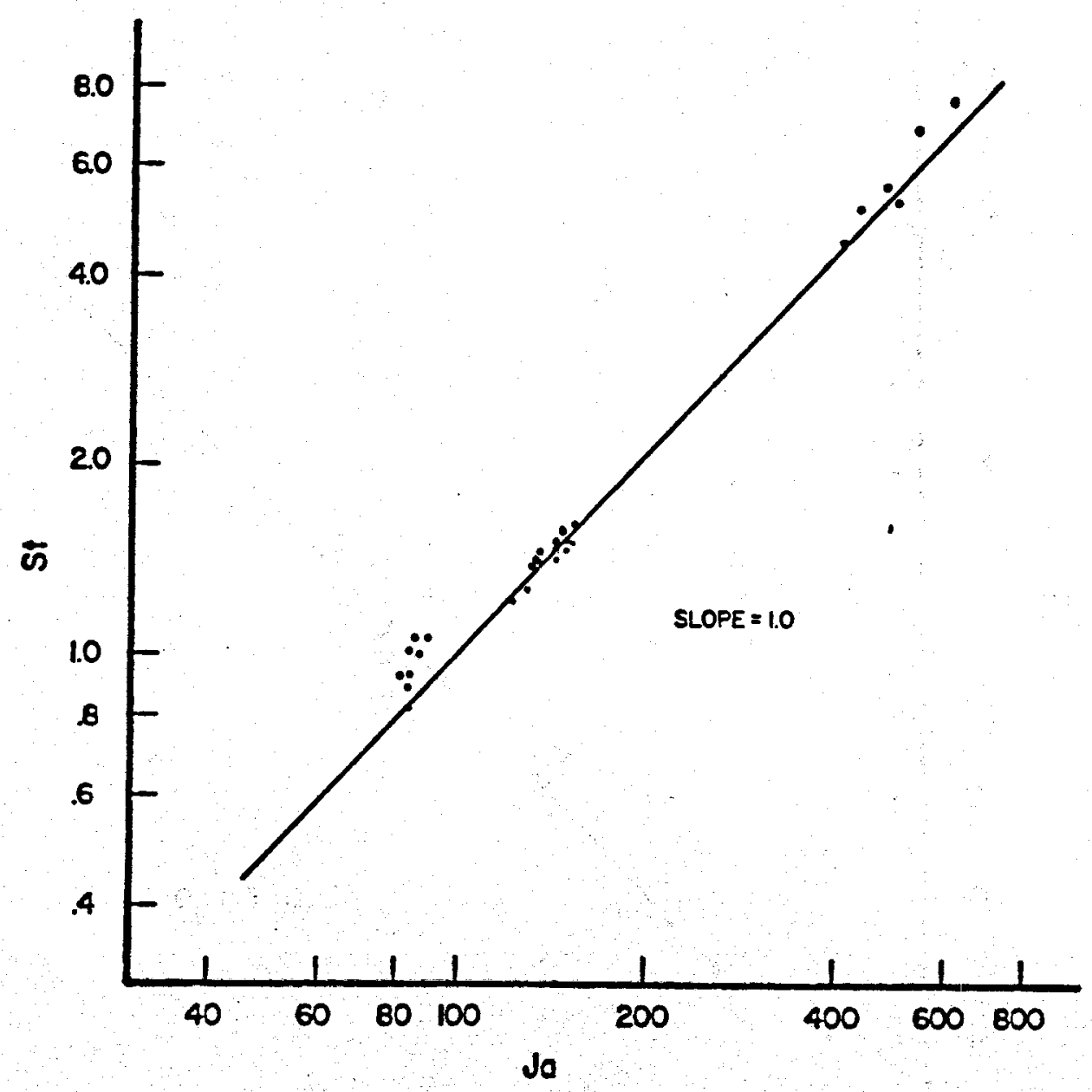

Figure 11. Effect of Ja on St for Steam Condensing on Aroclor in a 66 High Bed of $2.5 \mathrm{~cm}$ Raschig rings

(Data was obtained by Cheng (8)) 


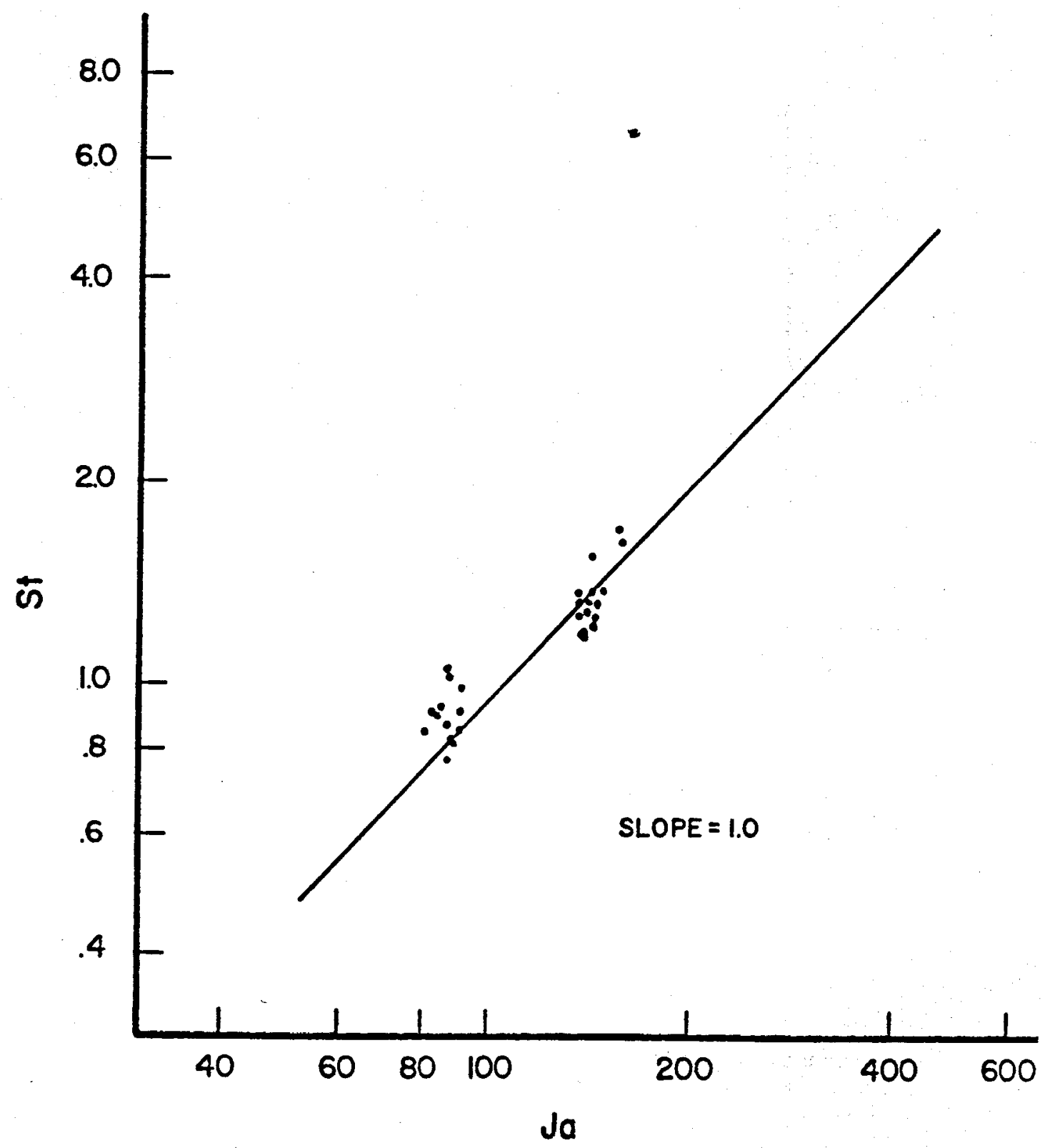

Figure 12. Effect of Ja on St for Steam Condensing on Aroclor in a $96 \mathrm{~cm}$ High Bed of $2.5 \mathrm{~cm}$ Raschig rings.

(Data was obtained by Cheng ( 8$)$ ). 
An estimation of the Stanton number dependence on this parameter was made from Figures 13, 14 and 15, where St/Ja versus C is plotted, and the data are grouped according to bed height. With the exception of the data for the $96 \mathrm{~cm}$ bed height of the Aroclor-water system, the data correlate reasonably well for each height grouping, and may be approximated by a line of slope -0.21 . Therefore,

$$
\frac{S t}{\mathrm{Ja}} \sim \mathrm{c}^{-0.21}
$$

\section{Stanton Number Dependence on Bed Height}

In Figure 16 , the average value of $\mathrm{St} / \mathrm{Ja} \mathrm{C}^{-0.21}$ for all data obtained for each bed height is plotted against the non-dimensional height $H$, which is defined as the bed height divided by the characteristic size of the packing material. The Stanton number dependence on $H$, as determined from these figures, is $H^{-0.67}$. This result is confirmed by Figures 17 and 18 , where St verses $H$ is plotted and the data are grouped according to Ja; the slope is again approximately -0.67 . Thus,

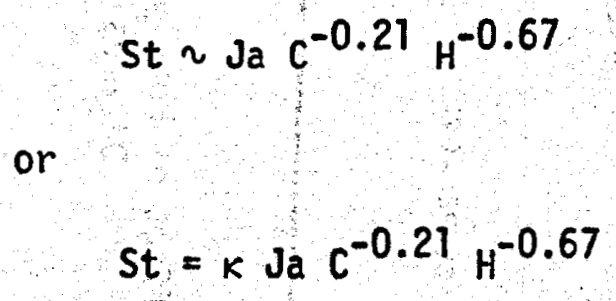

$$
S t=K J a C^{-0.21} H^{-0.67}
$$

\section{Determination of Proportionality Constants}

Agreement between the three systems for Stanton number dependence on Ja, $\mathrm{C}$ and $\mathrm{H}$ has been good. However, a different proportionality constant is required to correlate the data of each system. The proportionality constants for the spherical packing, Berl saddle packing, 


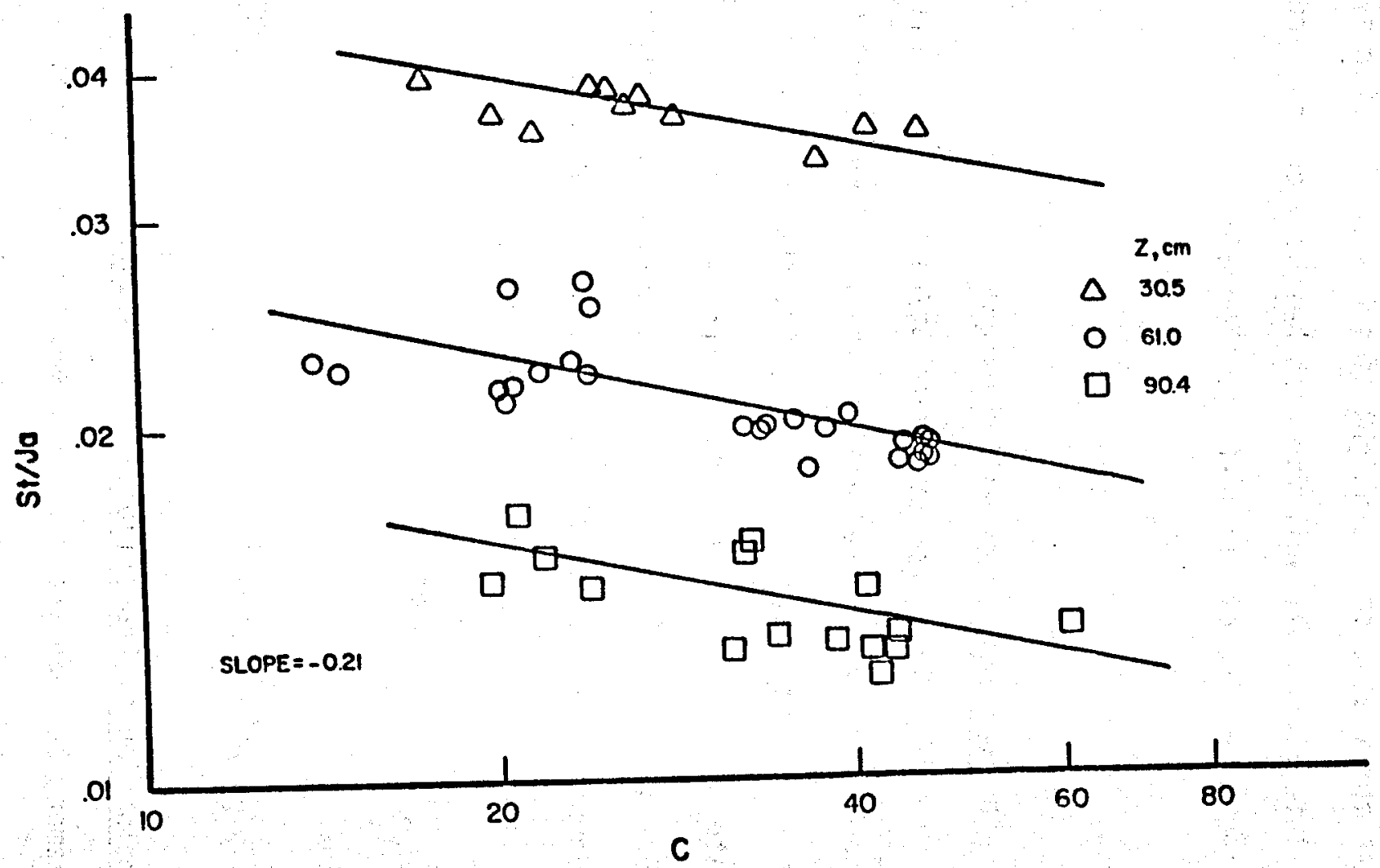

Figure 13. Effect of Hourly Heat Capacity Ratio on St/Ja for R-113 - water System Data Using $3.2 \mathrm{~cm}$ Diameter Spherical Packing 


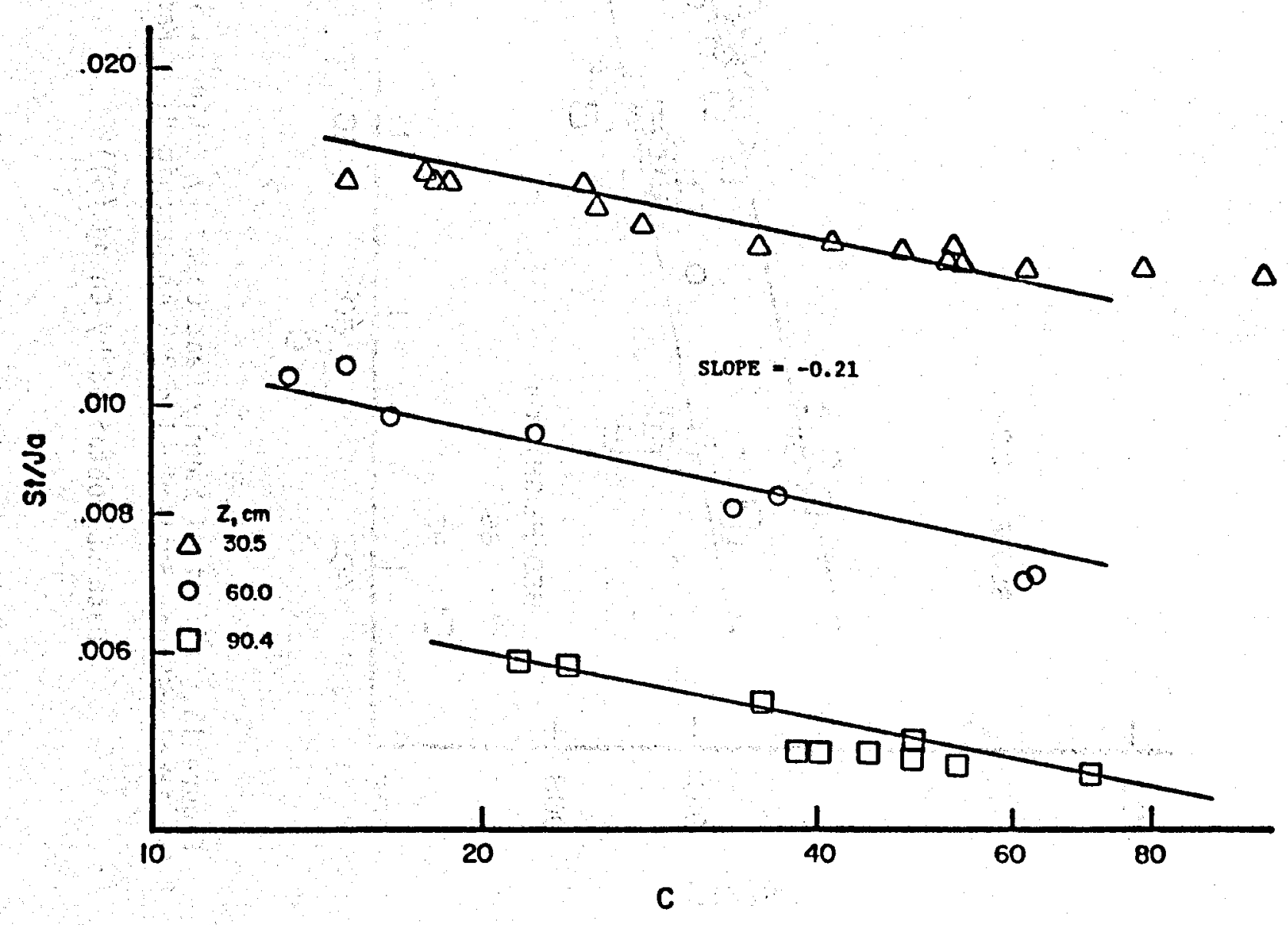

Figure 14. Effect of Hourly Heat Capacity Ratio on St/Ja for R-113 - water System Data Using $2.5 \mathrm{~cm}$ Berl Saddle Packing 


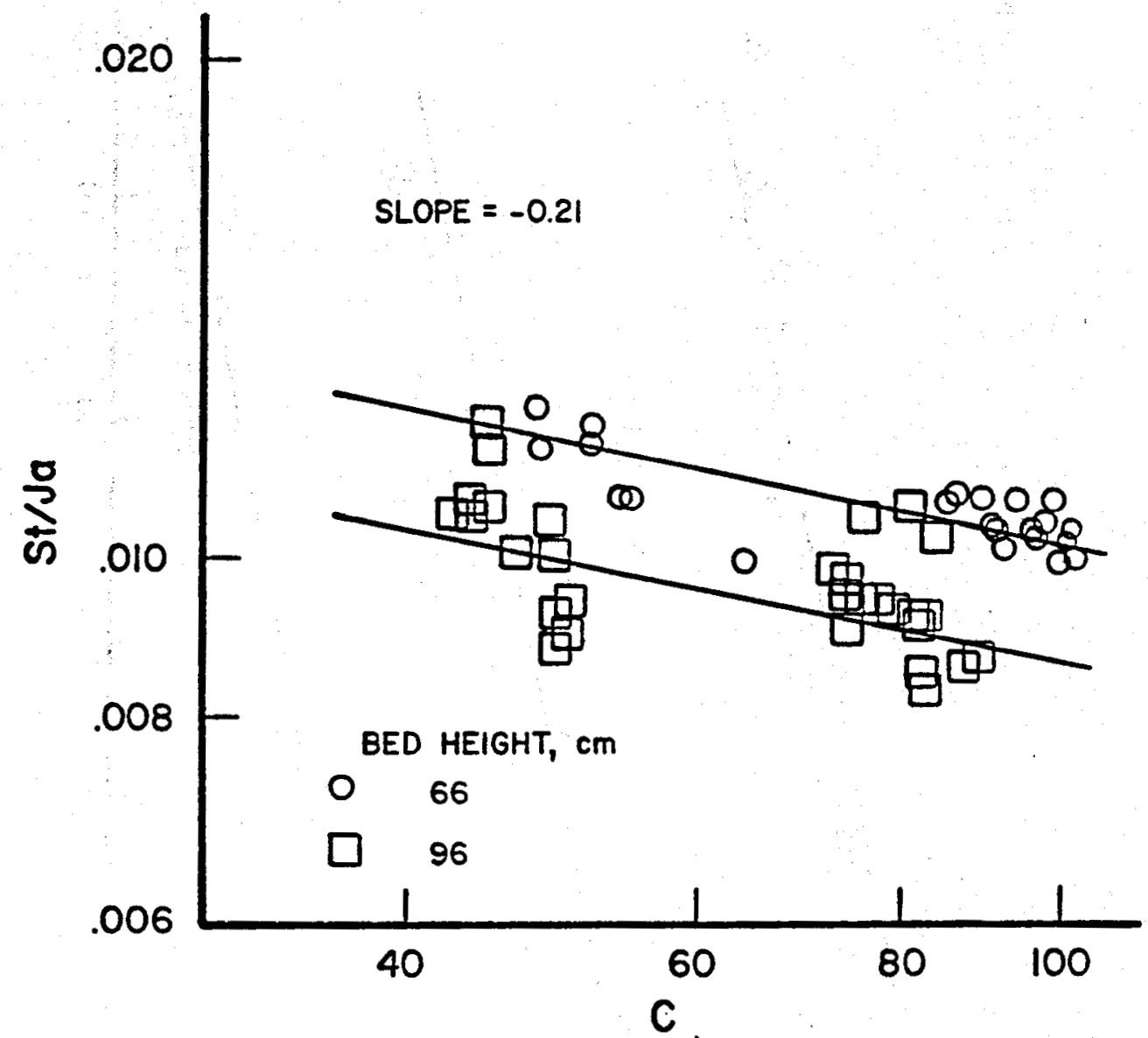

Figure 15. Effect of Hourly Heat Capacity Ratio on St/Ja for Aroclor-Steam System using $2.5 \mathrm{~cm}$ Raschig Ring Packing (Data was obtained by Cheng (8)) 


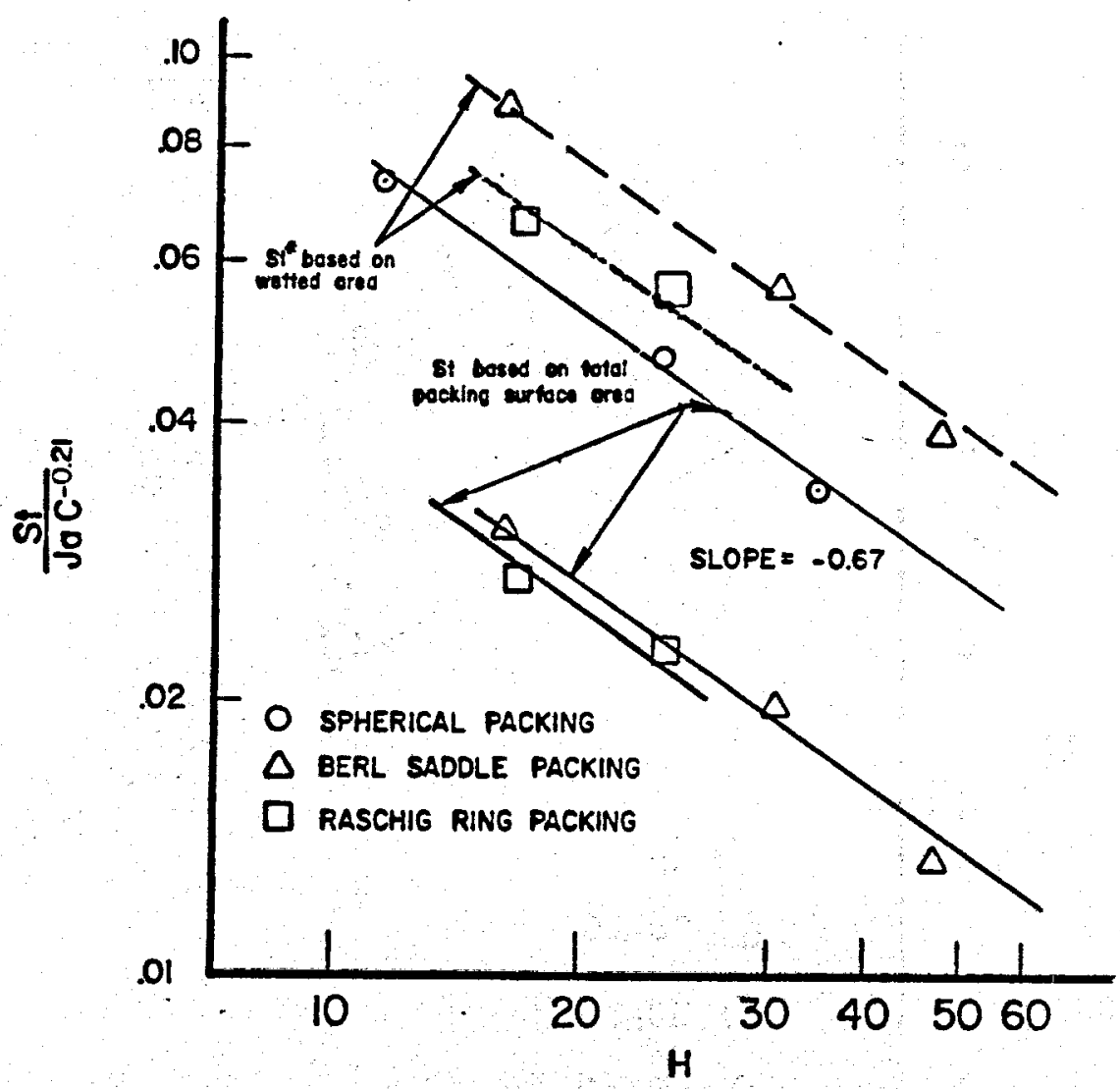

Figure 16. Correlation of Data with Respect to Non-dimensional Height $H$

Note: Figure includes correlation of Aroclor-steam (Raschig ring packing) data obtained by Cheng as well as $R-113$ - water data obtained in the present study. 


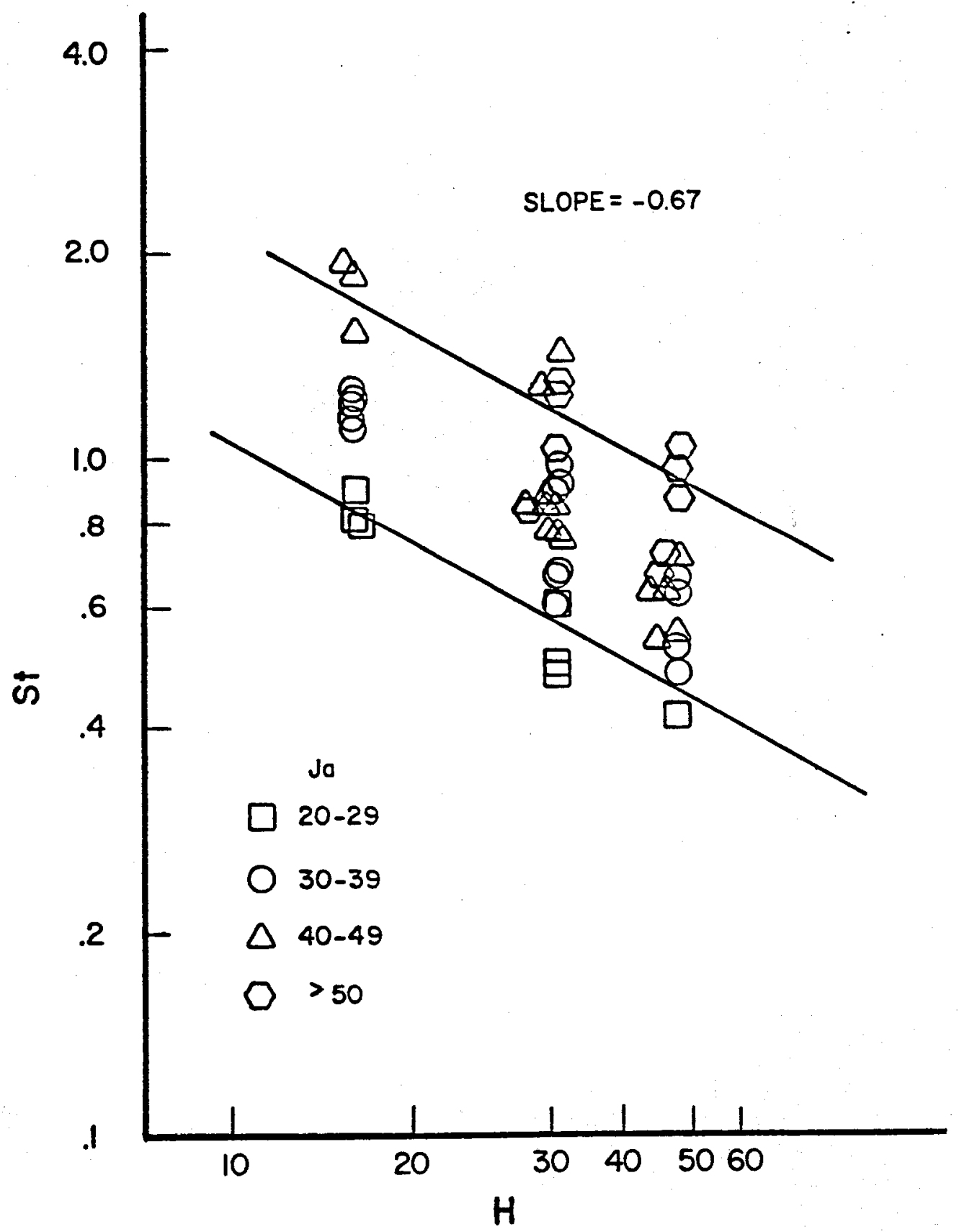

Figure 17. Effect of $\mathrm{H}$ on Stanton Number for R-113 - water System Using $3.2 \mathrm{~cm}$ Spherical Packing 


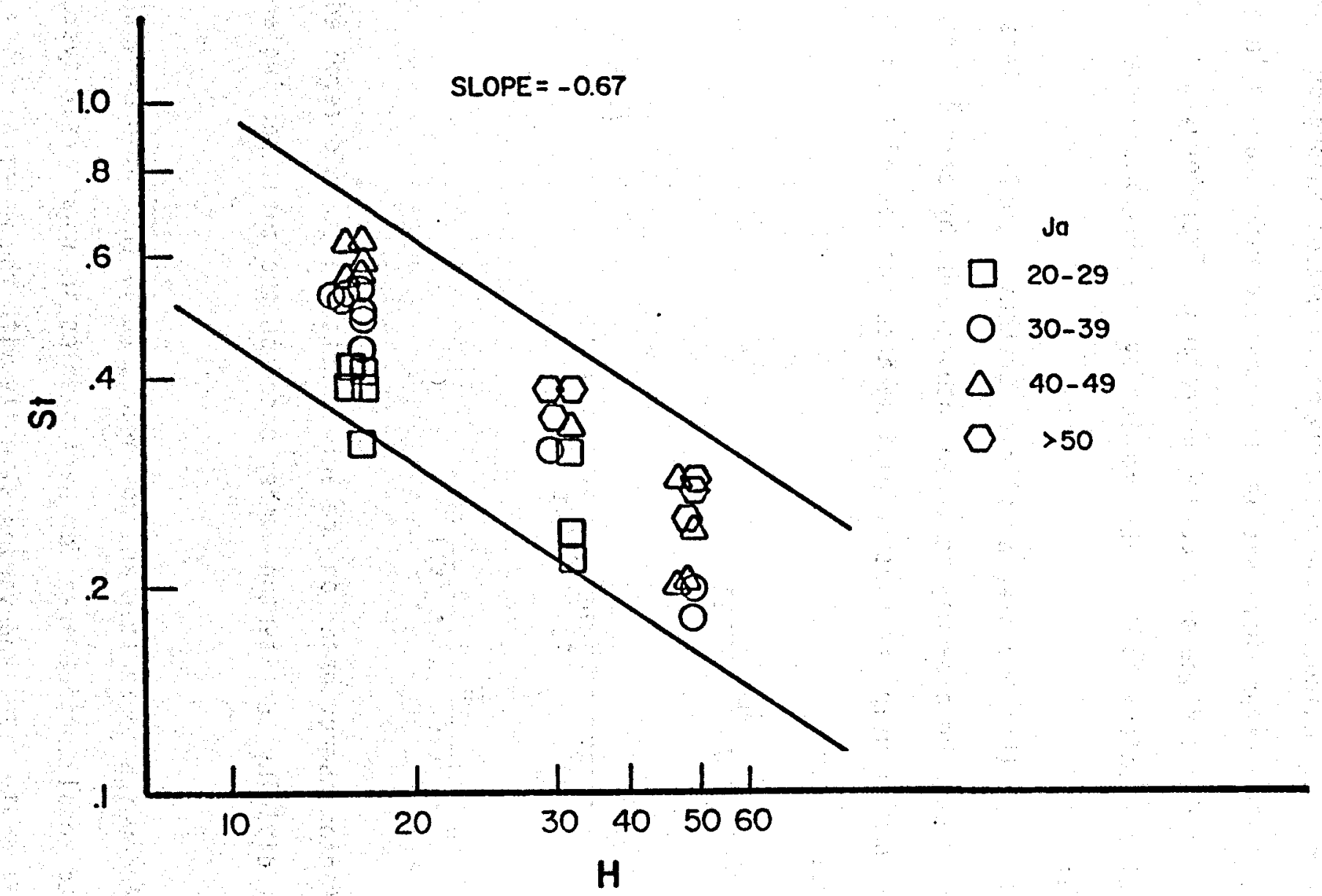

Figure 18. Effect of $\mathrm{H}$ on Stanton Number for $\mathrm{R}-113$ - water System Using $2.5 \mathrm{~cm}$ Berl Saddle Packing 
and Raschig ring systems are $.342, .168$ and .158 respectively.

The discrepancy is due to the value of the packing surface area per unit volume, a, used in the definition of the Stanton number. Unlike the spherical packing, which was completely wetted throughout the range of liquid flow rates, Berl saddles and Raschig rings have a large proportion of dry surface area during operation. Therefore, the parameter $a$ is not sufficient to describe completely the area available for heat transfer.

The fact that the area available for heat transfer is less than the total packing area may be taken into account by calculating the Stanton number using the wetted packing area instead of the total packing area. Then

$$
\begin{aligned}
S t^{*} & =\frac{\overline{h_{a}}}{\rho_{v} v C_{p_{v}}\left(a_{w} / v\right)} \\
& =\frac{\overline{h a}}{\rho_{v} v C_{p_{v}}\left(a_{t} / v\right)\left(a_{w} / a_{t}\right)} \\
& =\frac{\overline{h a}}{\rho_{v} v C_{p_{v}} a\left(a_{w} / a_{t}\right)}
\end{aligned}
$$

The Stanton number based on the actual wetted area is determined by simply dividing the Stanton number based on the total packing area by $a_{w} / a_{t} \cdot$

According to Shumman and co-workers (22), the ratio of wetted area to total surface area for Berl saddles in a water-air system is approximately 0.35 , and varies slightly with the water-air mass flow ratio. If it is assumed that the slight wetted area dependence; and, 
consequently, the Stanton number dependence on $\dot{\mathrm{m}}_{\mathrm{L}} / \dot{\mathrm{m}}_{v}$ has already been taken into account in Equation 24 by the factor $c^{-0.21}$, the value of the proportionality constant for the Berl saddle data becomes .408 .

For Raschig rings in a water-air system, the ratio of wetted area to total surface area per unit volume is approximately 0.44 . Curves reported by ShuTman and co-workers indicate that a factor of 0.92 must be applied to this ratio to account for the difference in viscosity, density and surface tension of the Aroclor-steam system. The ratio of wetted area to total area is then approximately 0.405. Applying this to the data of the Aroclor-water system, the value of the proportionality constant becomes .390 .

A correlation for both the Berl saddle and Raschig ring data using the wetted packing area to determine St is shown in Figure 16 by the dashed and dotted lines respectively. Although the correlation for the data obtained using Berl saddle packing compares favorably with the correlation for data obtained using sperical packing, a discrepancy is evident, even though both are Freon-water systems. Again, the disagreement is due to the difference between the total packing surface area and the effective wetted area.

Although the surface of the spherical packing was completely wetted, even at small flow rates, part of the surface was not effective for heat transfer. Specifically, the small area in the vicinity of the point of contact between adjacent spheres was wetted, but the liquid phase partialiy filled the volume between the spheres; and, thus, the surface area of the liquid phase exposed to vapor was slightly less than the total surface area of the bed of spheres. It is not known 
what proportion of the total bed area was effective in providing interfacial area between the liquid film and the vapor phase, but this fraction was just slightly less than 100 percent, and certainly much greater than 50 percent, as determined by visual observation.

In order for the data obtained using sperical packing to agree exactly with the Berl saddle data, the effective area of the spheres must be 84 percent of the total bed surface area. This seems entirely reasonable. While this may seem more like an argument for concluding that 84 percent of the total area is effective for condensation in a bed of spheres, rather than showing an exact agreement between data, the indication is that the appropriate value of the coefficient is approximately .400 for both types of packing. Thus, the final data correlation for the R-113 - water system is

$$
S t^{\star}=.400 \mathrm{Ja} \mathrm{C}-0.21 \mathrm{H}^{-0.67}
$$

for the Aroclor-steam system the correlation is

$$
S t *=.404 \mathrm{Ja} \mathrm{C}-0.21 H^{-0.67}
$$

Values of St predicted by Equations 26 and 27 are within 15 percent and 20 percent respectively of the measured values. In both correlations the Stanton number is based on the effective wetted area of the packing.

Since the coefficients in these two equations differ by only 14 percent, they lie within the margin of error of each other. Thus, it is very possible that the difference is due only to experimental error. Since the data for the R-113 - water system was more extensive, included results for more than one type of packing, and covered a wider 
range of bed heights, it is probable that the coefficient value of .40 is more accurate. Therefore, it is suggested that Equation 26 be used when estimating the heat transfer in liquid-vapor systems other than those discussed in this paper.

Coefficients obtained for a methylene chloride-water system using Equation 26 are similar to value in those obtained experimentally by Harriott and Wiegandt (7). From the data curve they reported, it is possible to determine ha for essentially only one flow condition: that of a liquid rate of $13.2 \times 10^{3} \mathrm{~kg} /\left(\mathrm{h} \cdot \mathrm{m}^{2}\right)$ at a vapor rate of $5.4 \times 10^{3}$ $\mathrm{kg} /\left(\mathrm{h} \cdot \mathrm{m}^{2}\right)$, with an approach temperature of $0.1{ }^{\circ} \mathrm{C}$. For this condition, Equation 26 predicts a volumetric coefficient of $162 \times 10^{4} \mathrm{~W} /\left(\mathrm{m}^{3} \cdot{ }^{\circ} \mathrm{C}\right)$ as compared to the value of $176 \times 10^{4} \mathrm{~W} /\left(\mathrm{m}^{3} \cdot{ }^{\circ} \mathrm{C}\right)$ obtained experimentally. This is a difference of 8.2 percent.

\section{B. Comments on the Correlation Equation}

As shown in the previous section, the correlation of the Aroclorsteam data and the correlation of the R-113 - water system data are in close agreement. This is very good considering the large dissimilarities between the two systems. One of the most apparent differences is the relative thermal conductivity of the liquid and condensate phase. In the Aroclor-steam system, the condensate film that forms between the coolant and the vapor has a much higher thermal conductivity than the Aroclor; and, hence, has almost negligible resistance compared to that of the coolant. In the R-113 - water system, however, the condensate film has a much lower thermal conductivity than the coolant; and, consequently, has been suspected to be responsible for a significant proportion of the total thermal resistance. 
Another striking difference between the two systems is the viscosity of the liquid phase. The ratio of Aroclor viscosity to water viscosity is approximately 13. The influence of this factor was taken into account in determining the wetted area of the column packing. Due to the close agreement between correlations, it is believed that the viscosity of the liquid layer does not influence the process significantly in any other way.

\section{Comparison with Previous Work}

Limited data obtained by Harriott and Wiegandt (7) for a methylene chloride - water system, using $1.3 \mathrm{~cm}(1 / 2-i n c h)$ Intalox saddles, indicate a volumetric heat transfer coefficient dependence on liquid phase flow rate to the 0.4 to 0.6 power. An attempt at a similar correlation of the data obtained in the present study is shown in Figures 19,20,21, 22, 23 and 24 . As seen from these figures, the data do not correlate well on this type of plot. Not only does the data scatter badly on each plot, but also the slope of the best fit line varies considerably. The range is from 0.2 to 0.8 . As these plots cover a range of bed heights, and no trend is seen, a general conclusion as to the volumetric coefficient dependence on liquid rate cannot be made. A similar plot of Cheng's (8) data is also nonrevealing. Perhaps, if enough data were available so that grouping according to Jakob number or average bed temperature could be made, a trend might appear, and a general conclusion would be possible. In effect, this is what was done in Section A-2, with good results, by plotting the non-dimensional heat transfer coefficient St divided by the Jakob number versus the non-diemsnional flow rate $C$. 


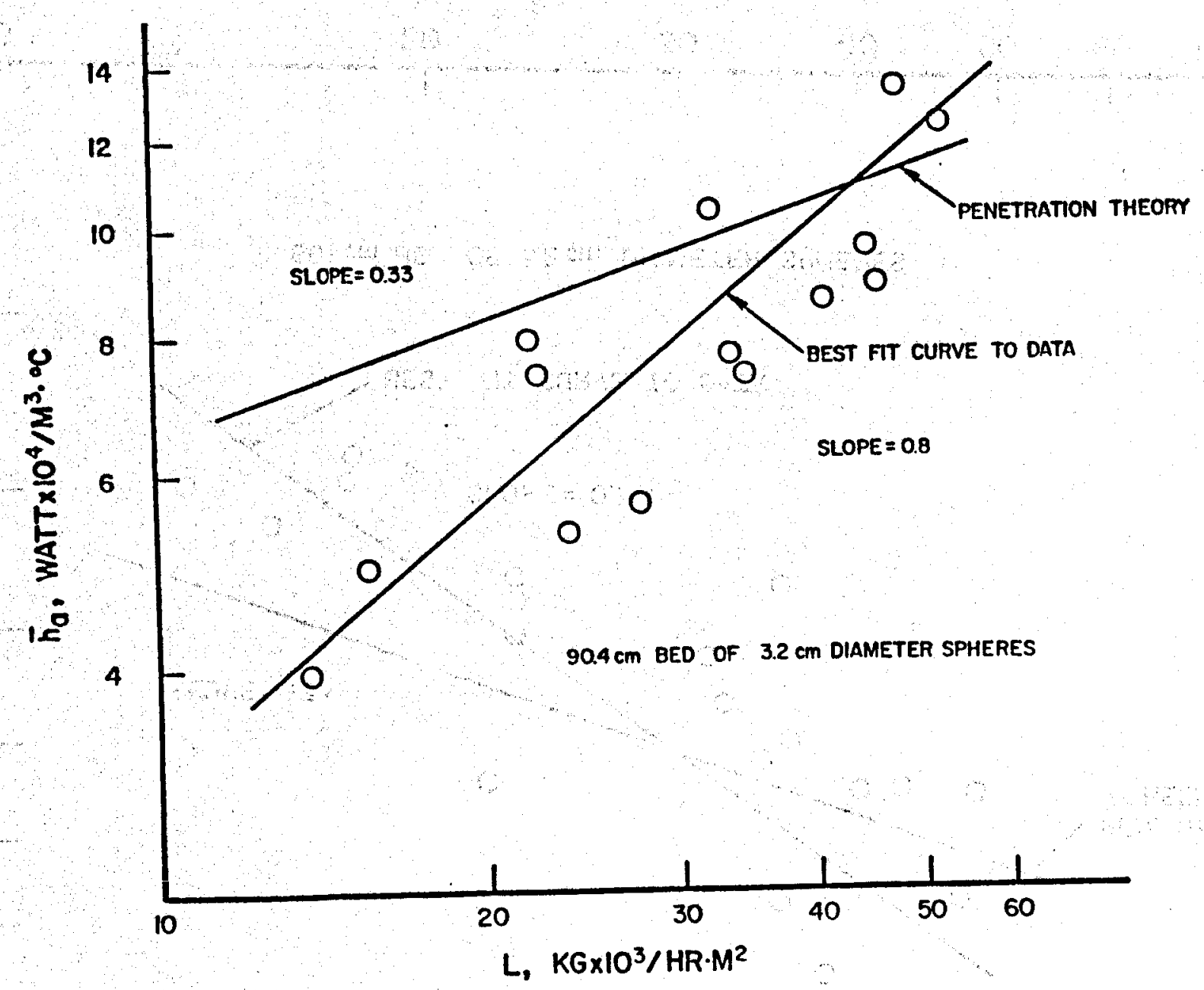

Figure 19. Effect of Liquid Phase Flow Rate on ha for R-113 - water System 


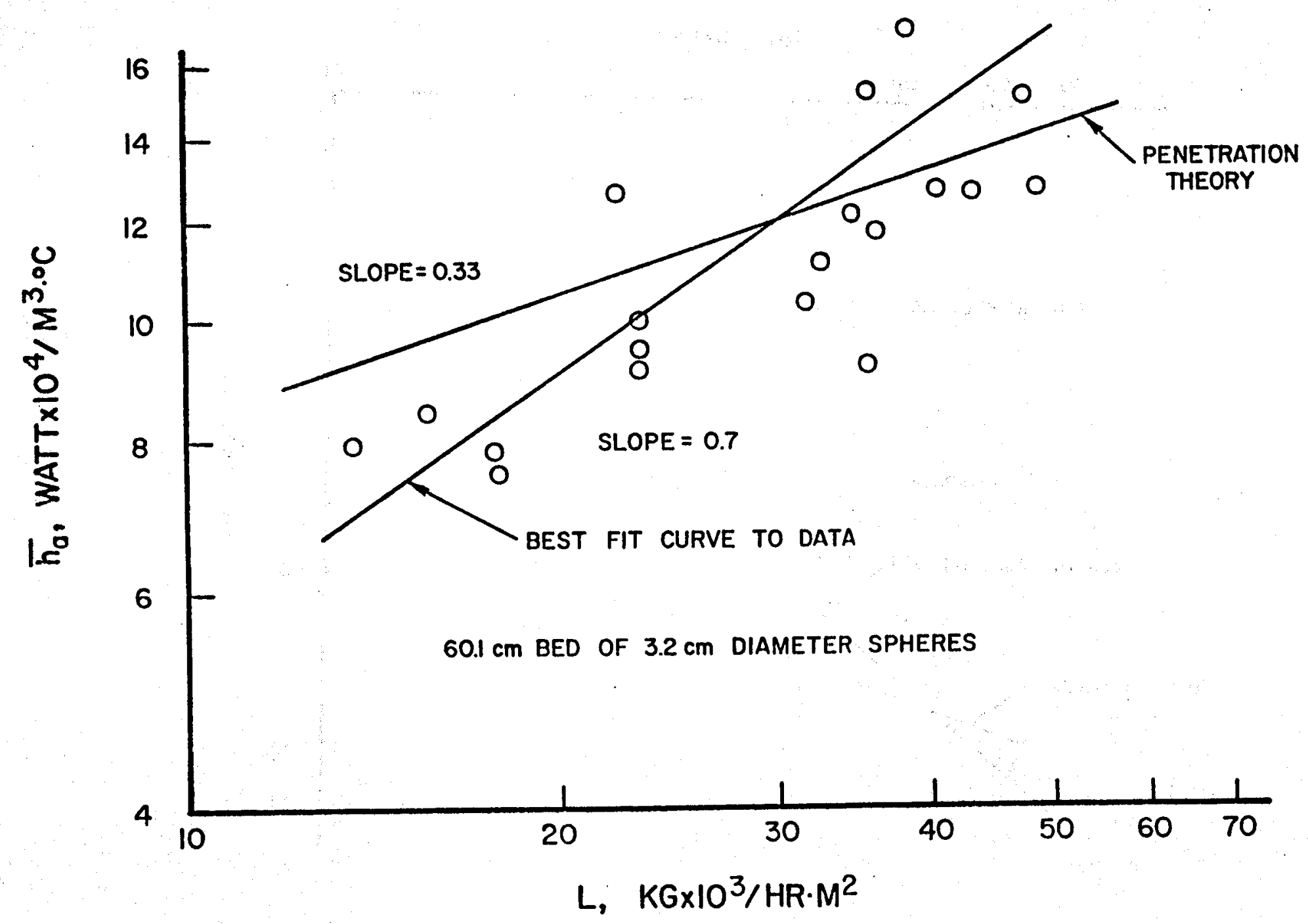

Figure 20. Effect of Liquid Phase Flow Rate on ha for R-113 - water System 


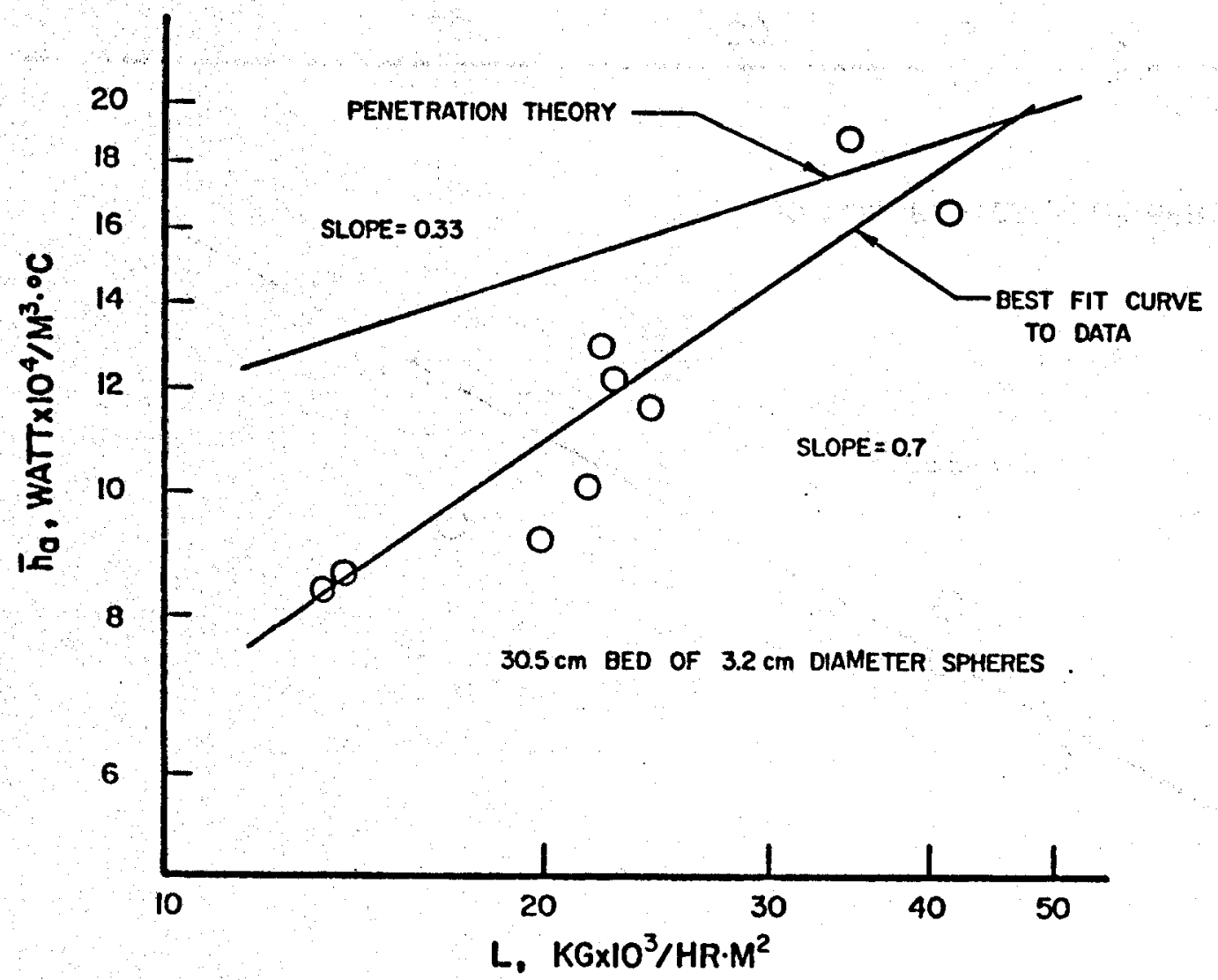

Figure 21. Effect of Liquid Phase Flow Rate on ha for R-113 - water System 


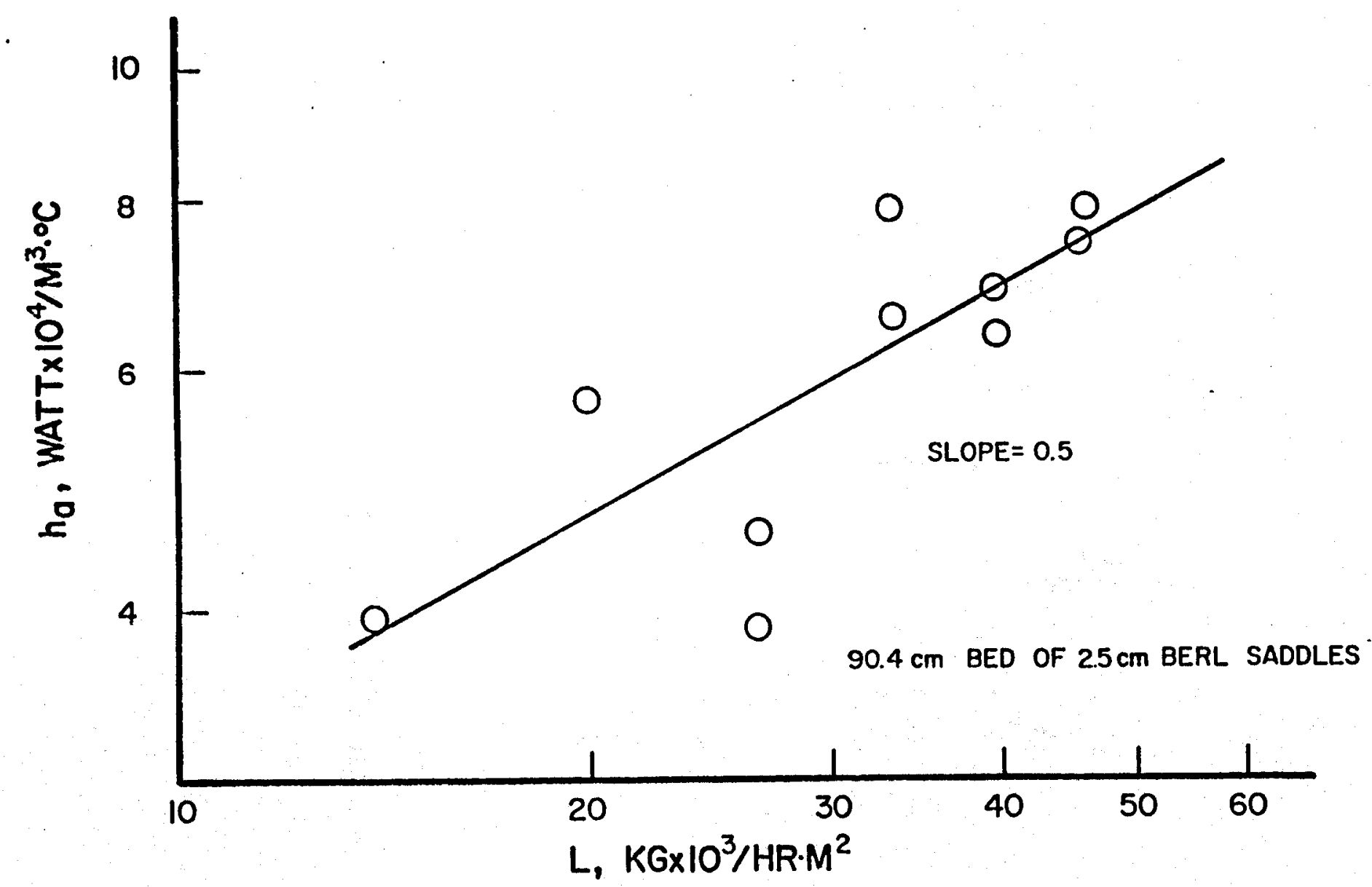

Figure 22. Effect of Liquid Phase Flow Rate on ha for R-113 - water System 


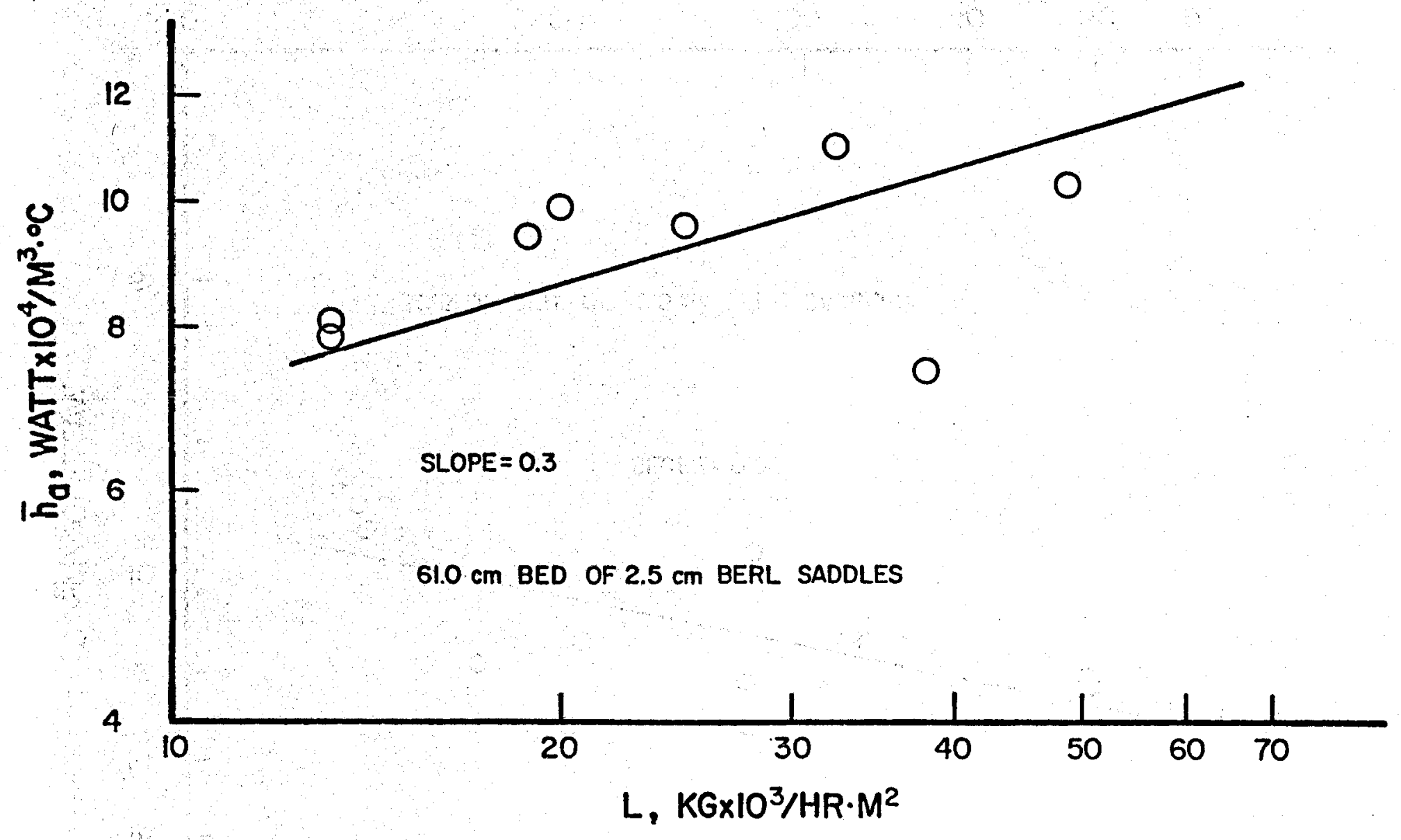

Figure 23. Effect of Liquid Phase Flow Rate on ha for R-113 - water System 


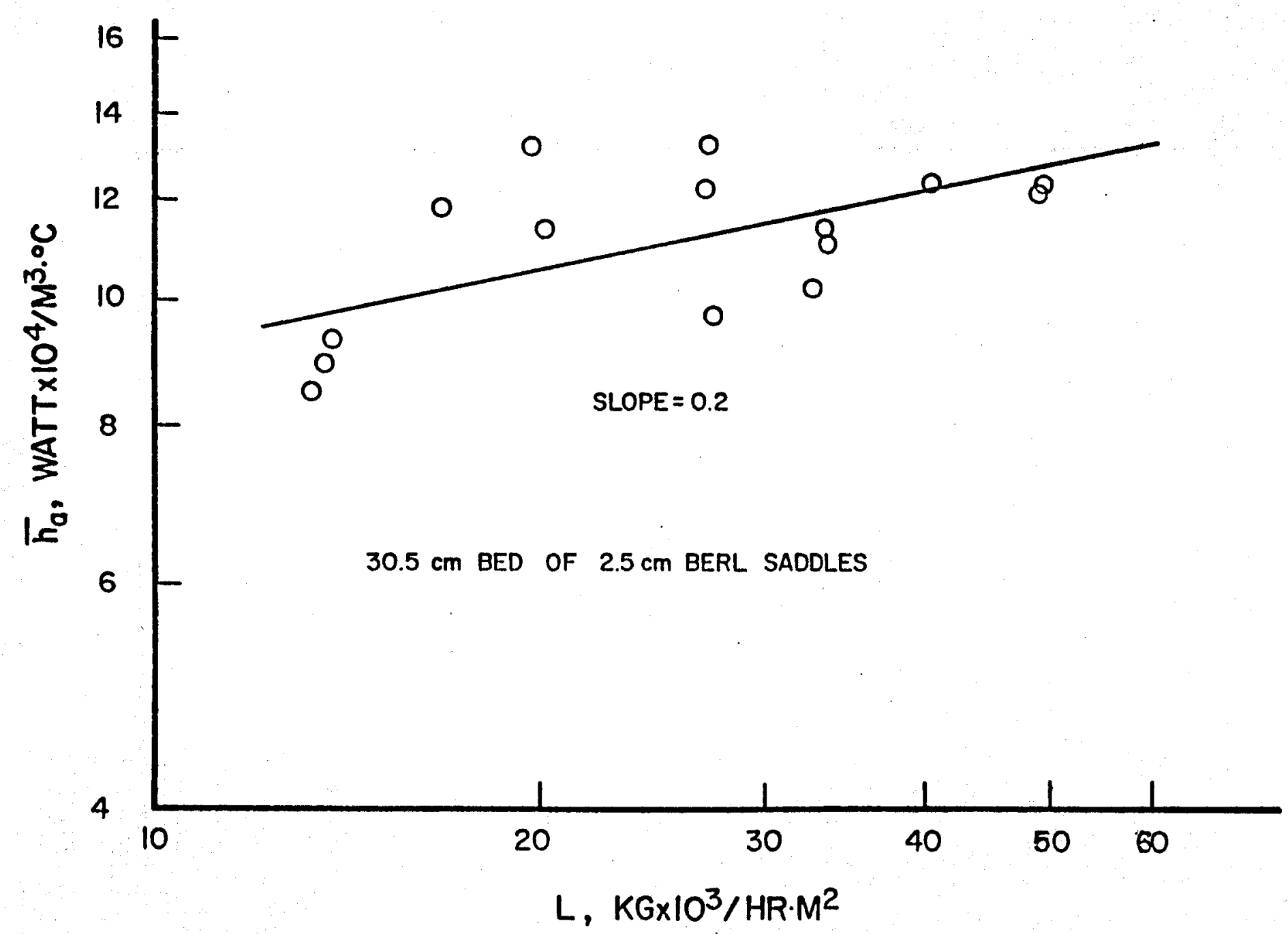

Figure 24. Effect of Liquid Phase Flow Rate on ha for R-113 - water System 
Values of the volumetric heat transfer coefficient obtained by Cheng for the Aroclor-steam system ranged from 7 to $13 \mathrm{~W} \cdot 10^{4} /\left(\mathrm{m}^{3} \cdot{ }^{\circ} \mathrm{C}\right)$. This is similar to the range of 3.7 to $19 \mathrm{~W} \cdot 10^{4} /\left(\mathrm{m}^{3} \cdot{ }^{\circ} \mathrm{C}\right)$ obtained in this investigation. Harriott and Wiegandt obtained volumetric coefficient values much greater, in the 93 to $290 \mathrm{~W} \cdot 10^{4} /\left(\mathrm{m}^{3} \cdot{ }^{\circ} \mathrm{C}\right)$ range. These large values of ha are due to the extremely close approach temperatures at which the condenser was operated. Approach temperatures from 0.1 to $0.3^{\circ} \mathrm{C}$ were attained, and such small temperature differences greatly affected the LMTD from which ha was determined; thus, giving extremely large coefficient values.

\section{Simplified Penetration Theory Results}

Equation 18, which was developed from penetration theory, predicts the volumetric heat transfer coefficient for condensation in a column packed with spheres as a function of the liquid flow rate, $l$, and the column height, $Z$. The parameter $l$ is the volumetric flow rate of the liquid phase over a single spherical packing element. When the total liquid flow rate, $\dot{m}_{L}$, through the column is known, the value of $\ell$ may be estimated by dividing $\dot{m}_{L}$ by the approximate number of spheres at a cross section of the column. For the $3.2 \mathrm{~cm}$ diameter spheres and the $14.6 \mathrm{~cm}$ diameter column used in this study, the approximate number of spheres at a cross section of the column is 16 , as determined by actual count. For a given liquid phase flow rate, therefore, the volumetric heat transfer coefficient predicted by Equation 18 may be compared to the experimental value by using the realtionship $\ell=L A / 16$. 
The effect of the liquid phase flow rate on the volumetric heat transfer coefficient as predicted by Equation 18 is compared to the experimental results in figures 19,20 and 21 . The theoretical result has a much smaller variation of ha with liquid flow rate than was obtained experimentally. Since the liquid flow rate has a stronger influence than predicted, the indication is that the depth of penetration is significantly greater than the infinitesimal depth assumed in the penetration theory. This suggests that the liquid film thickness and velocity profile should be included in any theoretical analysis of this process. Also, the fact that the coefficients are greater than the experimental values means that the actual thermal resistance is greater than predicted by penetration theory. Since penetration theory neglects interfacial resistance, this result indicates that interfacial resistance might be appreciable and should also be included in a theoretical analysis of direct contact condensation of immiscible fluids, especially when the thermal conductivity of the condensate is low compared to that of the liquid film. 


\section{CONCLUSIONS}

The results of this study indicate that packed bed heat transfer for condensation processes may be estimated within reasonable accuracy by the correlation:

$$
S t^{*}=.40 \mathrm{Ja} \mathrm{C}^{-0.21} \mathrm{H}^{-0.67}
$$

Inherent within this relationship are the conclusions that:

1. The volumetric heat transfer coefficient is inversely proportional to the difference between the saturation temperature and the average bed temperature.

2. The volumetric coefficient decreases with increasing bed height to the -0.67 power, 1.e. ha $\sim z^{-0.67}$.

3. The value of ha is not a simple function of the liquid flow rate or the vapor flow rate alone; however, a correlation with their ratio is possible.

4. Simplified penetration theory is inadequate to describe the heat transfer. 
VII. SUGGESTIONS FOR FUTURE WORK

1. Further experimentation with systems having different thermal properties is needed to test the conclusion that the slight difference in data between systems is due only to experimental error. If it is not, continued testing will reveal the factor needed to relate different 1 iquid-vapor systems.

2. Testing to determine the value of adding sensitizers to the liquid pahse in order to increase the rate of nuclei formation, and, thus, increase condensation.

3. Theoretical work modeling the interfacial resistance assuming 1) that is is due to the condesate $\mathrm{film}$, 2) that the resistance is due to nucleation phenomena. Such a study could aid in identifying any other significant parameters necessary to better correlate experimental data, and help ascertain the effect of adding sensitizers to the coolant. 


\section{APPENDIX I}

\section{DATA REDUCTION}

\section{A. Data Reduction Procedure}

The parameters measured during each run were: the water inlet temperature $t_{1}$, vapor inlet temperature $T_{2}$, mixture exit temperature $t_{2}$, water flow rate, $R-113$ flow rate, vessel pressure and the atmospheric pressure. A computer routine was written in Basic to reduce the data and determine St, Ja, C, HTU, NTU, and $\bar{h}$.

In order to follow the computer routine, it is necessary to understand the temperature distribution in a packed bed condenser. A qualitative diagram of the vessel temperature distribution is given in Figure 25. As shown, the bed consists of two regions, one a desuperheating zone and the other a condensation zone. The present study is concerned only with the analysis of the condensation zone; but, due to the method of generating vapor, it was difficult to prevent a small degree of superheating from occuring during operation, usually from 0 to $1.5^{\circ} \mathrm{C}$.

This problem was overcome by calculating the LMTD and NTU using the temperature $t_{c}$ of the liquid phase at the bottom of the condensation region, rather than the mixture temperature at the exit. $t_{c}$ was determined from a simple heat balance between the vapor and the liquid in the desuperheating region. $T_{2}$ and $t_{2}$ are known by direct measurement, and $T_{\text {sat }}$ is determined from the absolute vessel pressure. 


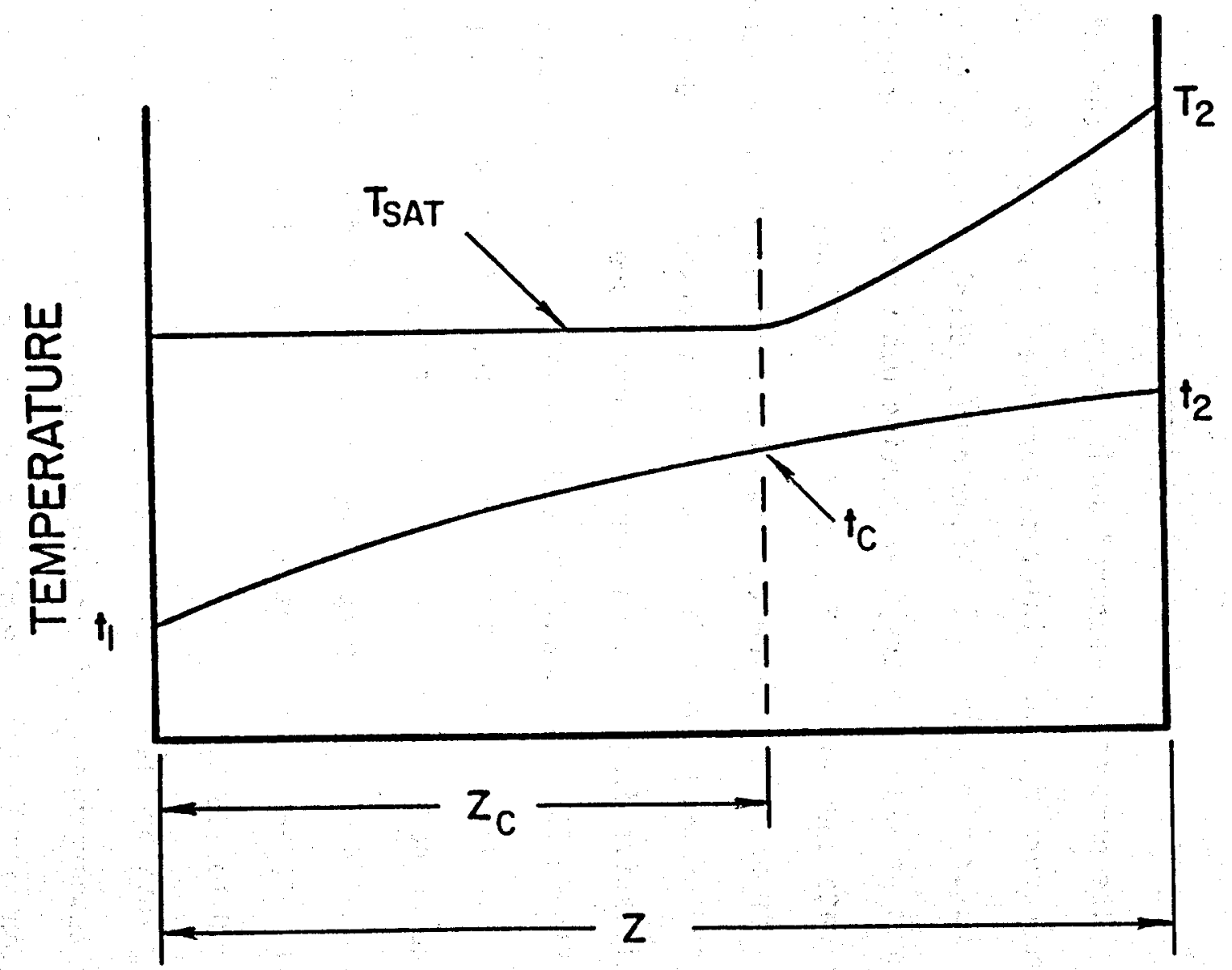

Figure 25. Qualitative Temperature Distribution in a Packed Bed Condenser 
In a study conducted by Cheng, it was determined theoretically and confirmed experimentally that the height of the condensation region could be estimated from

$$
Z_{c}=\frac{(N T U)_{c}}{(N T U)_{s a t}}
$$

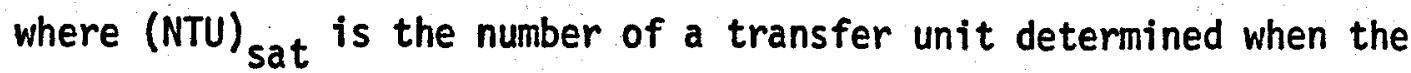
incoming vapor is saturated, and (NTU) ${ }_{c}$ is the number of a transfer unit in the condensation region when the incoming vapor is superheated. (NTU) sat $_{\text {and (NTU) }}$ must be determined at the same liquid flow rate and averaged bed temperature. Since the degree of superheating could not be controlled, values of (NTU) sat could not be obtained for all liquid flow rates; therefore, $z_{c}$ could not be calculated in most cases. However, for the cases when (NTU) ${ }_{\text {sat }}$ was available, a value of (NTU) $c$ was determined by slightly reducing the vapor flow rate and superheating it as much as possible. The liquid flow rate and temperature were held constant. This procedure made it possible to determine $z_{c}$ for a number of flow conditions. It was concluded from this, that for the small amount of superheat occurring during normal operation, that the desuperheating region was extremely small, usually less than 1 percent of the total bed height. On this basis then, the fact that $Z_{c}$ was less than the total bed height was ignored in determining the volume of the condensation region, and the total bed volume was used. This means that the volumetric heat transfer coefficients obtained in this study are probably conservative.

The value of the liquid phase temperature $t_{c}$ leaving the condensation region was, however, calculated and used in determining 
the LMTD and NTU. $t_{c}$ was usually less than $0.3^{\circ} \mathrm{C}$ below the vessel exit temperature $t_{2}$. This corresponds to a change in the LMTD of less than 1 percent, therefore, for the accuracy of this study, the effect of the desuperheating region could have been neglected altogether. It is important, however, to understand the heat load existing in a packed bed.

\section{B. Computer Routine}

The computer routine, which was written in Real Time Basic language, calculates the thermal properties of R-113 from equations determined by fitting curves to published tabular data. All input data were in English units. The data were entered into a separate file for storage and combined with the main program by executing the EDIT MERGE command. A listing of all raw and reduced data, converted to metric units, is presented in Appendix II. The original computer print out compared $Q 1$ and $Q 2$. Runs in which this difference exceeded \pm 5 percent were discarded.

Statement 180 was included in the program to cause $\mathrm{H} 2$ in 1 ine 190 and the LMTD to be determined from the measured vapor inlet temperature $\mathrm{T} 3$ when, due to experimental error, the calculated saturation temperature T4 was greater than $T 3$.

Table 1 contains a listing of all variables used in the program. 


\section{TABLE 1.}

Variabies Used in Computer Routine

A Surface area of packing per unit volume, $f t^{2} / f t^{3}$.

C Ratio of hourly heat capacities, dimensionless.

D1. Temperature difference at the bottom of the condensation zone, ${ }^{\circ} \mathrm{F}$.

D2 Temperature difference at the top of the vessel, ${ }^{\circ} \mathrm{F}$.

H1 Enthalpy of condensate leaving the vessel, BTU/lb.

H2 Enthalpy of saturated liquid R-113, BTU/1b.

H3 Enthalpy of superheated R-113 vapor, BTU/Tb.

H4 Enthalpy of saturated R-113 vapor, BTU/1b.

H5 Latent heat of R-113, BTU/1b.

J Jakob number, dimensionless.

Mi Flow rate of water, gal/min.

M2 Flow rate of $R-113$, gal/min.

M3 Ratio of mass flow rates, dimensionless.

$N$ Run number.

P Absolute pressure in vessel, psi.

P1 Barometric pressure, in. $\mathrm{H}_{\mathrm{g}}$.

P2 Gauge pressure in vessel, in. $\mathrm{H}_{2} \mathrm{O}$.

Q Heat gained by coolant in condesnation zone, BTU/hr.

Q1 Heat gained by coolant in vesse1, BTU/hr.

Q2 R-113 heat loss, BTU/hr.

$R$ Density of condensate, $1 \mathrm{~b} / \mathrm{ft}^{3}$. 
S Stanton number, dimensionless.

T HTU, ft.

$\mathrm{Tl}$ Inlet coolant temperature, ${ }^{\circ} \mathrm{F}$.

T2 Exit temperature of coolant-condensate mixture, ${ }^{\circ} \mathrm{F}$.

T3 Vapor inlet temperature, ${ }^{\circ} \mathrm{F}$.

T4 R-113 saturation temperature, ${ }^{\circ} \mathrm{F}$.

T5 Log mean temperature difference in condensation region, ${ }^{\circ} \mathrm{F}$.

T6 Temperature of coolant leaving the condensation zone, ${ }^{\circ} \mathrm{F}$.

$U$ Volumetric heat transfer coefficient, BTU/hr $\mathrm{ft}^{3}{ }^{\circ} \mathrm{F}$.

W NTU, dimensiontess.

$Z$ Bed height, ft. 


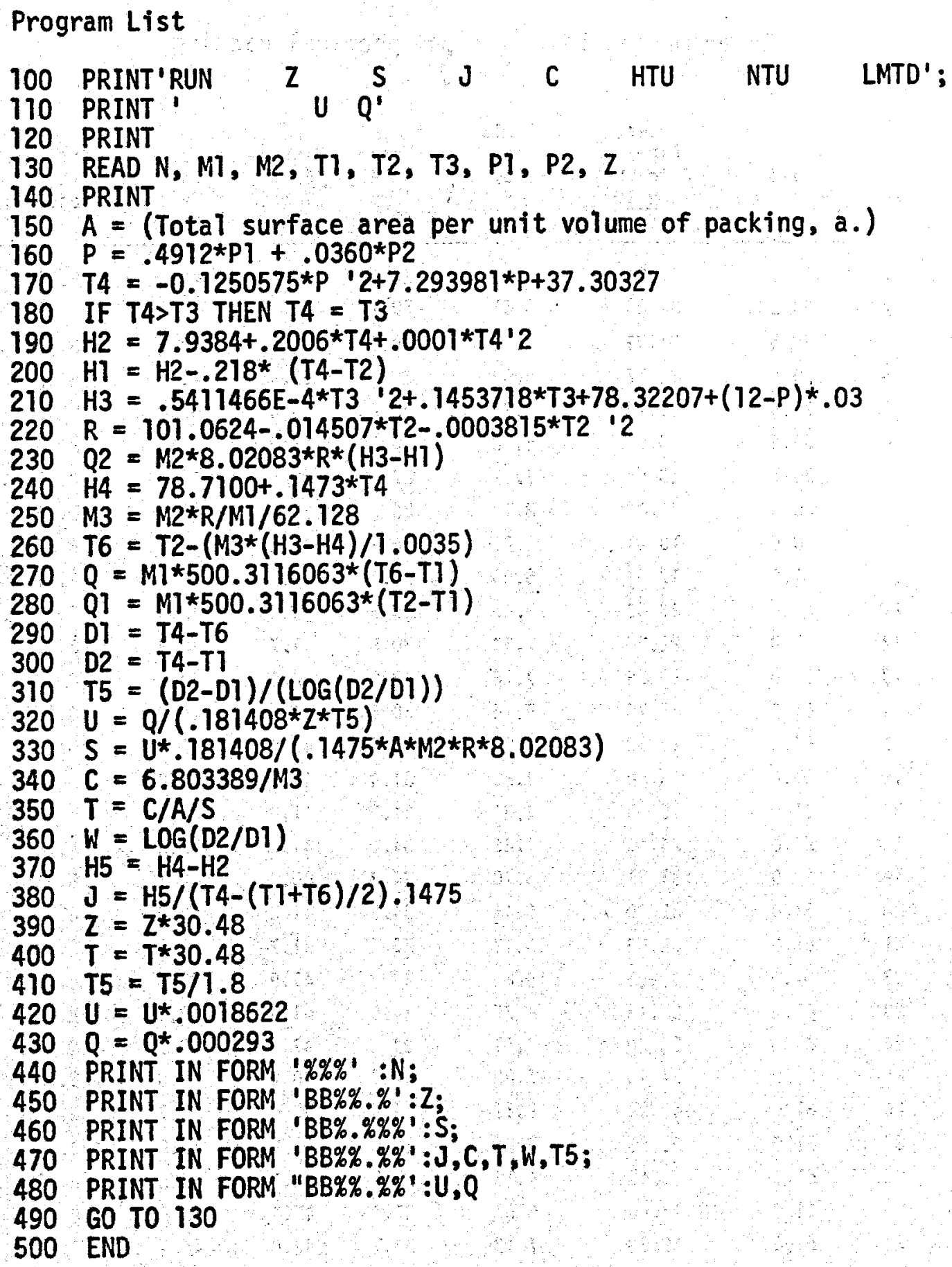




\section{APPENDIX II}

TABLE 2

Experimental Data $3.2 \mathrm{~cm}$ Spherical Packing

\begin{tabular}{|c|c|c|c|c|c|c|c|}
\hline Run & $\underset{\substack{\text { Bed } \\
\text { Height, } \\
\text { (cm) }}}{ }$ & $\begin{array}{c}\text { Water } \\
\text { Flow } \\
\text { Rate, } L \\
\left(\frac{K G \times 10^{3}}{(\text { Hr Sq } M}\right)\end{array}$ & $\begin{array}{c}R-113 \\
\text { Flow } \\
\text { Rate, } \\
\left(\begin{array}{l}K G \times 10^{2} \\
\text { Hr Sq } M\end{array}\right)\end{array}$ & $\begin{array}{l}\text { Water } \\
\text { Inlet } \\
\text { Temp. } \\
\left({ }^{\circ} \mathrm{C}\right)\end{array}$ & $\begin{array}{l}\text { Mixture } \\
\text { Exit } \\
\text { Temp. } \\
\left({ }^{\circ} \mathrm{C}\right)\end{array}$ & $\begin{array}{l}\text { Vapor } \\
\text { Inlet } \\
\text { Temp. } \\
\left({ }^{\circ} \mathrm{C}\right)\end{array}$ & $\begin{array}{c}\text { Absolute } \\
\text { Vesse1 } \\
\text { Pressure, } \\
\left(\mathrm{Pa} \times 10^{4}\right)^{\mathrm{P}}\end{array}$ \\
\hline 1 & 30.5 & 41.03 & 6.05 & 34.2 & 39.5 & 42.3 & 8.50 \\
\hline 2 & 30.5 & 34.05 & 8.61 & 30.1 & 39.2 & 42.0 & 8.50 \\
\hline 3 & 30.5 & 21.99 & 5.94 & 29.8 & 39.5 & 42.1 & 8.50 \\
\hline 4 & 30.5 & 22.52 & 5.82 & 30.1 & 39.4 & 42.5 & 8.50 \\
\hline 5 & 30.5 & 13.94 & 3.79 & 30.2 & 40.4 & 53.6 & 8.50 \\
\hline 6 & 30.5 & 19.84 & 4.70 & 30.2 & 38.9 & 46.5 & 8.50 \\
\hline 7 & 30.5 & 23.06 & 7.17 & 27.1 & 38.5 & 45.6 & 8.87 \\
\hline 8 & 30.5 & 24.00 & 8.18 & 26.0 & 38.5 & 45.6 & 8.75 \\
\hline 9 & 30.5 & 13.41 & 5.21 & 26.2 & 40.2 & 43.6 & 8.87 \\
\hline 10 & $61.0^{-}$ & 17.97 & 5.09 & 31.4 & 41.5 & 42.7 & 8.93 \\
\hline 11 & 61.0 & 23.33 & 7.66 & 30.5 & 42.2 & 43.9 & 8.93 \\
\hline 12 & 61.0 & 22.26 & 7.33 & 30.0 & 41.7 & 42.3 & 8.93 \\
\hline 13 & 61.0 & 23.06 & 7.76 & 30.0 & 42.0 & 43.7 & 8.93 \\
\hline 14 & 61.0 & 17.70 & 5.16 & 30.5 & 40.9 & 42.0 & 8.93 \\
\hline 15 & 61.0 & 23.33 & 7.26 & 29.8 & 40.9 & 42.2 & 8.93 \\
\hline 16 & 61.0 & 13.68 & 3.89 & 31.4 & 41.5 & 42.0 & 8.93 \\
\hline 17 & 61.0 & 15.55 & 4.37 & 31.0 & 41.0 & 41.6 & 8.93 \\
\hline 18 & 61.0 & 24.13 & 4.86 & 34.0 & 41.2 & 42.8 & 8.92 \\
\hline 19 & 61.0 & 31.91 & 5.70 & 34.3 & 40.7 & 42.1 & 8.92 \\
\hline 20 & 61.0 & 32.40 & 6.11 & 34.8 & 41.6 & 42.9 & 8.92 \\
\hline 21 & 61.0 & 35.53 & 16.42 & 25.2 & 41.7 & 43.6 & 8.92 \\
\hline 22 & 61.0 & 38.21 & 18.63 & 24.5 & 41.9 & 43.8 & 8.92 \\
\hline 23 & 61.0 & 23.18 & 4.29 & 34.5 & 41.4 & 53.1 & 8.92 \\
\hline 24 & 61.0 & 36.20 & 7.61 & 34.6 & 42.1 & 43.9 & 8.92 \\
\hline 25 & 61.0 & 34.46 & 5.88 & 34.8 & 40.9 & 42.0 & 8.92 \\
\hline 26 & 61.0 & 40.22 & 8.12 & 34.8 & 42.0 & 43.7 & 8.92 \\
\hline 27 & 61.0 & 35.53 & 5.35 & 36.5 & 41.9 & 44.8 & 8.92 \\
\hline 28 & 61.0 & 28.42 & 4.18 & 36.7 & 42.0 & 46.2 & 8.92 \\
\hline 29 & 61.0 & 42.90 & 6.58 & 36.8 & 42.3 & 45.5 & 8.92 \\
\hline 30 & 61.0 & 48.53 & 7.19 & 36.7 & 42.0 & 44.2 & 8.92 \\
\hline 31 & 61.0 & 47.59 & 6.95 & 36.8 & 42.0 & 43.2 & 8.92 \\
\hline 32 & 91.4 & 15.69 & 4.88 & 30.0 & 41.1 & 42.1 & 9.02 \\
\hline 33 & 91.4 & 16.76 & 5.74 & 30.1 & 42.3 & 43.7 & 9.02 \\
\hline
\end{tabular}


Table 2 continued

\begin{tabular}{llllllllll}
34 & 91.4 & 13.81 & 3.93 & 30.5 & 40.7 & 41.9 & 9.02 \\
\hline 35 & 91.4 & 22.12 & 7.22 & 30.6 & 42.2 & 42.9 & 9.02 \\
36 & 91.4 & 22.52 & 4.74 & 34.2 & 41.7 & 42.3 & 9.02 \\
37 & 91.4 & 23.73 & 4.70 & 34.3 & 41.4 & 42.9 & 8.90 \\
38 & 91.4 & 27.75 & 5.97 & 34.3 & 42.0 & 43.9 & 9.02 \\
39 & 91.4 & 32.31 & 6.70 & 34.2 & 41.6 & 42.2 & 8.92 \\
40 & 91.4 & 52.02 & 5.82 & 37.9 & 41.9 & 42.6 & 9.01 \\
41 & 91.4 & 33.65 & 5.26 & 36.0 & 41.6 & 42.7 & 8.93 \\
42 & 91.4 & 41.03 & 6.76 & 36.0 & 41.9 & 43.3 & 8.81 \\
43 & 91.4 & 47.46 & 7.86 & 36.4 & 42.3 & 43.0 & 8.81 \\
44 & 91.4 & 45.72 & 7.38 & 36.0 & 41.8 & 43.0 & 8.93 \\
45 & 91.4 & 44.91 & 7.90 & 36.1 & 42.4 & 44.5 & 8.93 \\
46 & 91.4 & 34.86 & 5.45 & 36.3 & 41.9 & 43.2 & 8.93
\end{tabular}


Table 3

Experimental: Data $2.5 \mathrm{~cm}$ Berl Saddle Packing

\begin{tabular}{|c|c|c|c|c|c|c|c|}
\hline Run & $\begin{array}{l}\text { Bed } \\
\text { Height, } Z \\
(\mathrm{~cm})\end{array}$ & $\begin{array}{l}\text { Water } \\
\text { Flow } \\
\text { Rate, } L \\
\left(\frac{\text { KG } \times 10^{3}}{\text { Hr Sq } M}\right)\end{array}$ & $\begin{array}{c}\text { R-113 } \\
\text { Flow } \\
\text { Rate, } G \\
\left(\begin{array}{l}\text { KG } X \cdot 10^{3} \\
\text { Hr Sq } M\end{array}\right)\end{array}$ & $\begin{array}{l}\text { Water } \\
\text { Inlet } \\
\text { Temp: } \\
\left({ }^{\circ} \mathrm{C}\right)\end{array}$ & $\begin{array}{l}\text { Mixture } \\
\text { Exit } \\
\text { Temp. } \\
\left({ }^{\circ} \mathrm{C}\right)\end{array}$ & $\begin{array}{l}\text { Vapor } \\
\text { Inlet } \\
\text { Temp. } \\
\left({ }^{\circ} \mathrm{C}\right)\end{array}$ & $\begin{array}{l}\text { Absolute } \\
\text { Vessel } \\
\text { Pressure } \mathrm{P} \\
\left(\mathrm{Pa} \times 10^{4}\right)\end{array}$ \\
\hline 1 & 30.5 & 13.41 & 5.96 & 22.1 & 38.2 & 42.0 & 8.55 \\
\hline 2 & 30.5 & 13.68 & 5.11 & 26.1 & 39.6 & 43.4 & 8.55 \\
\hline 3 & 30.5 & 19.84 & 7.28 & 26.0 & 39.2 & 42.2 & 8.55 \\
\hline 4 & 30.5 & 16.76 & 6.39 & 26.0 & 39.7 & 42.2 & 8.55 \\
\hline 5 & 30.5 & 13.94 & 3.85 & 30.0 & 39.9 & 42.0 & 8.54 \\
\hline 6 & 30.5 & 20.11 & 5.37 & 30.1 & 39.7 & 42.7 & 8.54 \\
\hline 7 & 30.5 & 27.08 & 6.60 & 30.0 & 38.8 & 42.3 & 8.54 \\
\hline 8 & 30.5 & 33.79 & 6.49 & 30.0 & 37.0 & 41.9 & 8.54 \\
\hline 9 & 30.5 & 26.81 & 4.41 & 33.9 & 39.8 & 42.4 & 8.54 \\
\hline 10 & 30.5 & 32.71 & 4.22 & 34.1 & 38.8 & 44.2 & 8.54 \\
\hline 11 & 30.5 & 49.07 & 4.22 & 35.9 & 39.0 & 42.4 & 8.54 \\
\hline 12 & 30.5 & 27.35 & 3.88 & 34.0 & 39.2 & 46.5 & 8.53 \\
\hline 13 & 30.5 & 33.79 & 4.31 & 34.1 & 38.7 & 42.0 & 8.53 \\
\hline 14 & 30.5 & 40.22 & 5.12 & 34.0 & 38.6 & 42.3 & 8.53 \\
\hline 15 & 30.5 & 49.20 & 5.42 & 34.0 & 38.0 & 42.4 & 8.53 \\
\hline 16 & 30.5 & 20.38 & 2.56 & 34.2 & 39.0 & 56.0 & 8.53 \\
\hline 17 & 30.5 & 47.59 & 2.31 & 35.5 & 37.4 & 60.0 & 8.53 \\
\hline 18 & 30.5 & 48.27 & 2.65 & 36.5 & 38.6 & 55.5 & 8.53 \\
\hline 91 & 61.0 & 13.41 & 6.03 & 25.2 & 41.2 & 41.9 & 8.88 \\
\hline 20 & 61.0 & 13.54 & 6.88 & 22.7 & 40.8 & 41.7 & 8.88 \\
\hline 21 & 61.0 & 18.77 & 7.73 & 26.0 & 40.7 & 41.8 & 8.51 \\
\hline 22 & 61.0 & 20.11 & 6.15 & 30.0 & 40.9 & 41.8 & 8.51 \\
\hline 23 & 61.0 & 24.94 & 4.60 & 34.0 & 40.6 & 41.6 & 8.50 \\
\hline 24 & 61.0 & 32.31 & 6.42 & 34.0 & 41.1 & 42.5 & 8.67 \\
\hline 25 & 61.0 & 38.61 & 4.27 & 36.1 & .40 .1 & 42.6 & 8.50 \\
\hline 26 & 61.0 & 48.94 & 5.29 & 36.4 & 40.3 & 42.2 & 8.50 \\
\hline 27 & 91.4 & 14.08 & 4.00 & 30.0 & 40.2 & 41.4 & 8.50 \\
\hline 28 & 91.4 & 20.11 & 6.30 & 30.0 & 41.2 & 42.5 & 8.75 \\
\hline 29 & 97.4 & 26.81 & 4.07 & 34.0 & 39.4 & 41.4 & 8.70 \\
\hline 30 & 91.4 & 33.52 & 6.35 & 34.0 & 40.8 & 42.0 & 8.75 \\
\hline 31 & · $\quad 91.4$ & 40.22 & 7.14 & 34.1 & 40.5 & 42.7 & 8.67 \\
\hline 32 & 91.4 & 46.92 & 7.92 & 34.1 & 40.2 & 42.5 & 8.50 \\
\hline 33 & 91.4 & 46.92 & 5.99 & 36.3 & 40.9 & 42.7 & 8.77 \\
\hline 34 & 91.4 & 40.22 & 4.67 & 36.2 & 40.4 & 42.0 & 8.63 \\
\hline 35 & 91.4 & 33.52 & 4.57 & 36.3 & 41.2 & 42.5 & 8.85 \\
\hline 36 & 91.4 & 26.81 & 2.59 & 36.9 & 40.4 & 42.0 & 8.82 \\
\hline
\end{tabular}


Table 4

Calculated Experimental Results $3.2 \mathrm{~cm}$ Spherical Packing

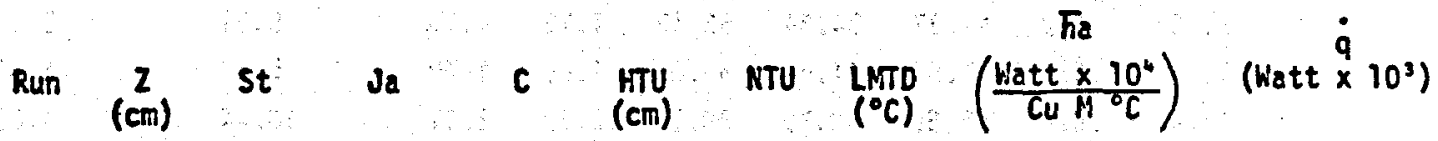

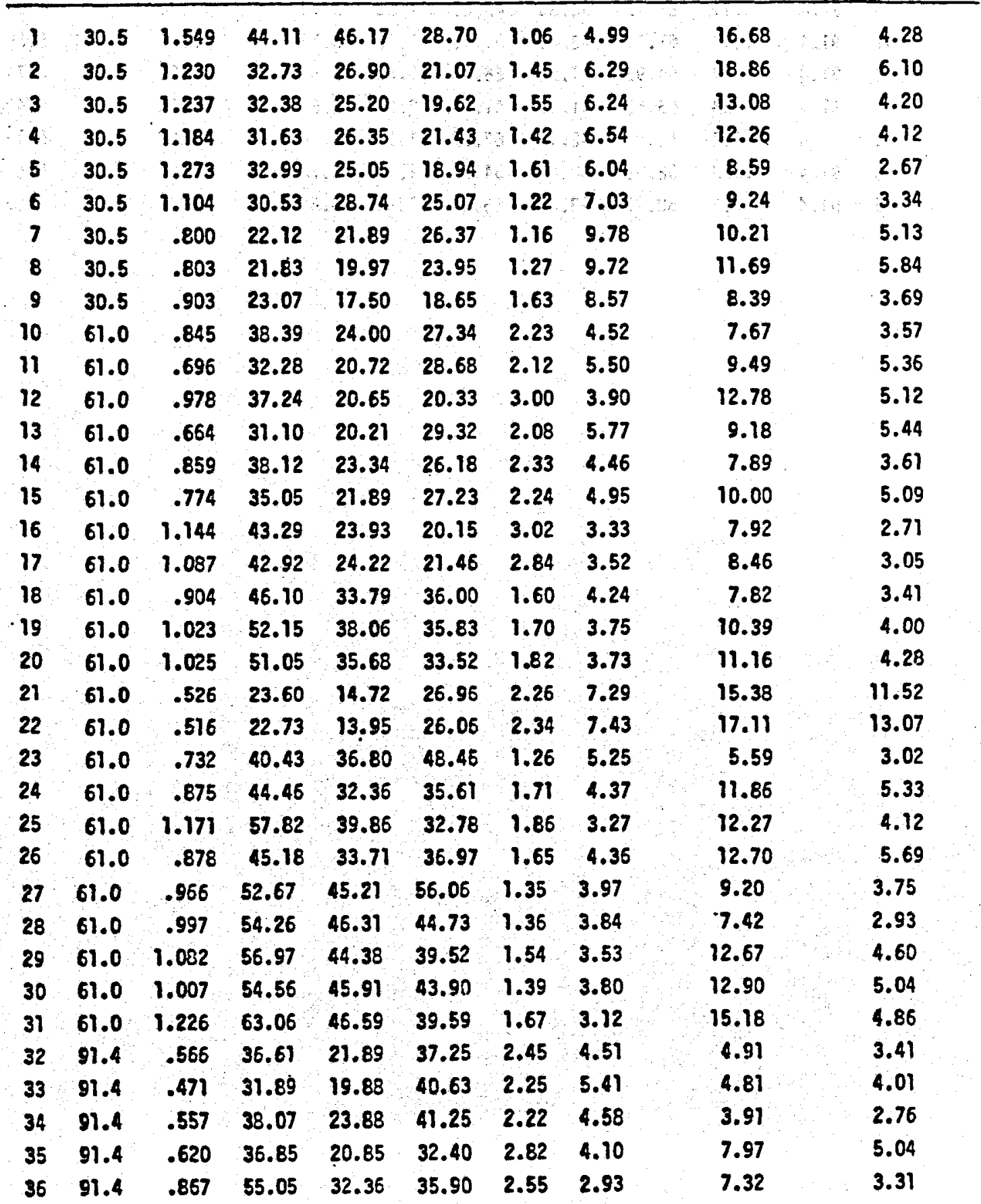


Table 4 continued

\begin{tabular}{rrrrrrrrrrr}
37 & 91.4 & .622 & 47.37 & 34.34 & 53.13 & 1.72 & 4.10 & 5.21 & 3.30 \\
\hline 38 & 91.4 & .534 & 41.55 & 31.64 & 57.08 & 1.60 & 4.70 & 5.67 & 4.19 \\
39 & 91.4 & .874 & 55.69 & 32.79 & 36.11 & 2.53 & 2.91 & 10.44 & 4.68 \\
40 & 91.4 & 1.191 & 88.45 & 60.85 & 49.20 & 1.86 & 2.14 & 12.34 & 4.06 \\
41 & 91.4 & .813 & 61.31 & 43.49 & 51.53 & 1.77 & 3.14 & 7.62 & 3.68 \\
42 & 91.4 & .707 & 54.93 & 41.28 & 56.20 & 1.63 & 3.61 & 8.52 & 4.74 \\
43 & 91.4 & .953 & 65.50 & 41.09 & 41.54 & 2.20 & 2.67 & 13.33 & 5.48 \\
44 & 91.4 & .597 & 48.84 & 42.13 & 67.92 & 1.35 & 4.28 & 7.86 & 5.18 \\
45 & 91.4 & .683 & 52.52 & 38.69 & 54.54 & 1.68 & 3.73 & 9.61 & 5.52 \\
46 & 91.4 & .753 & 58.29 & 43.48 & 55.64 & 1.64 & 3.39 & 7.31 & 3.82
\end{tabular}


Table 5

Calculated Experimental Results $2.5 \mathrm{~cm}$ Berl Saddle Packing

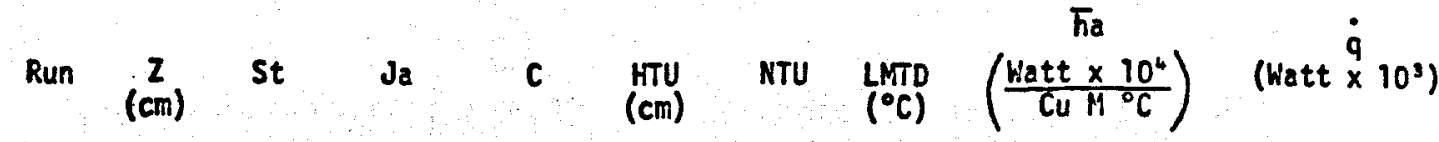

\begin{tabular}{|c|c|c|c|c|c|c|c|c|c|}
\hline 1 & 30.5 & 1.549 & 44.11 & 46.17 & 28.70 & 1.06 & 4.99 & 16.68 & 4.28 \\
\hline 2 & 30.5 & 1.230 & 32.73 & 26.90 & 21.07 & 1,45 & 6.29 & 18.86 & 6.10 \\
\hline 3 & 30.5 & 1.237 & 32.38 & 25.20 & 19.62 & 1.55 & 6.24 & 13.08 & 4.20 \\
\hline 4 & 30.5 & 1.184 & 31.63 & 26.35 & 21.43 & 1.42 & 6.54 & 12.26 & 4.12 \\
\hline 5 & 30.5 & 1.273 & 32.99 & 25.05 & 18.94 & 1.61 & 6.04 & 8.59 & 2.67 \\
\hline 6 & 30.5 & 1.104 & 30.53 & 28.74 & 25.07 & 1.22 & 7.03 & 9.24 & 3.34 \\
\hline 7 & 30.5 & .800 & 22.12 & 21.89 & 26.37 & 1.16 & 9.78 & 10.21 & 5.13 \\
\hline 8 & 30.5 & .803 & 21.83 & 19.97 & 23.95 & 1.27 & 9.72 & 11.69 & 5.84 \\
\hline 9 & 30.5 & .903 & 23.07 & 17.50 & 18.65 & 1.63 & 8.57 & 8.39 & 3.69 \\
\hline 10 & 61.0 & .845 & 38.39 & 24.00 & 27.34 & 2.23 & 4.52 & 7.67 & 3.57 \\
\hline$n$ & 61.0 & .696 & 32.28 & 20.72 & 28.68 & 2.12 & 5.50 & 9.49 & 5.36 \\
\hline 12 & 61.0 & .978 & 37.24 & 20.65 & 20.33 & 3.00 & 3.90 & 12.78 & 5.12 \\
\hline 13 & 61.0 & .664 & 31.10 & 20.21 & 29.32 & 2.08 & 5.77 & 9.18 & 5.44 \\
\hline 14 & 61.0 & .859 & 38.12 & 23.34 & 26.18 & 2.33 & 4.46 & 7.89 & 3.61 \\
\hline 15 & 61.0 & .774 & 35.05 & 21.89 & 27.23 & 2.24 & 4.95 & 10.00 & 5.09 \\
\hline 16 & 61.0 & 1.144 & 43.29 & 23.93 & 20.15 & 3.02 & 3.33 & 7.92 & 2.71 \\
\hline 17 & 61.0 & 1.087 & 42.92 & 24.22 & 21.46 & 2.84 & 3.52 & 8.46 & 3.05 \\
\hline 18 & 61.0 & .904 & 46.10 & 33.79 & 36.00 & 1,60 & 4.24 & 7.82 & 3.41 \\
\hline 19 & 61.0 & 1.023 & 52.15 & 38.06 & 35.83 & 1.70 & 3.75 & 10.39 & 4.00 \\
\hline 20 & 61.0 & 1.025 & 51.05 & 35.68 & 33.52 & 1.82 & 3.73 & 11.16 & 4.28 \\
\hline 21 & 61.0 & .526 & 23.60 & 14.72 & 26.96 & 2.26 & 7.29 & 15.38 & 11.52 \\
\hline 22 & 61.0 & .516 & 22.73 & 13.95 & 26.06 & 2.34 & 7.43 & 17.11 & 13.07 \\
\hline 23 & 61.0 & .732 & 40.43 & 36.80 & 48.45 & 1.26 & 5.25 & 5.59 & 3.02 \\
\hline 24 & 61.0 & .875 & 44.46 & 32.36 & 35.61 & 1.71 & 4.37 & 11.86 & 5.33 \\
\hline 25 & 61.0 & 1.171 & 57.82 & 39.86 & 32.78 & 1.86 & 3.27 & 12.27 & 4.12 \\
\hline 26 & 61.0 & .878 & 45.18 & 33.71 & 36.97 & 1.65 & 4.36 & 12.70 & 5.69 \\
\hline 27 & 61.0 & .966 & 52.67 & 45.21 & 56.06 & 1.35 & 3.97 & 9.20 & 3.75 \\
\hline 28 & 61.0 & .997 & 54.26 & 46.31 & 44.73 & 1.36 & 3.84 & 7.42 & 2.93 \\
\hline 29 & 61.0 & 1.082 & 56.97 & 44.38 & 39.52 & 1.54 & 3.53 & 12.67 & 4.60 \\
\hline 30 & 61.0 & 1.007 & 54.56 & 45.91 & 43.90 & 1.39 & 3.80 & 12.90 & 5.04 \\
\hline 31 & 61.0 & 1.226 & 63.06 & 46.59 & 39.59 & 1.67 & 3.12 & 15.18 & 4.86 \\
\hline 32 & 91.4 & .566 & 36.61 & 21.89 & 37.25 & 2.45 & 4.51 & 4.91 & 3.41 \\
\hline 33 & 91.4 & .471 & 31.89 & 19.88 & 40.63 & 2.25 & 5.41 & 4.81 & 4.01 \\
\hline 34 & 91.4 & .557 & 38.07 & 23.88 & 41.25 & 2.22 & 4.58 & 3.91 & 2.76 \\
\hline 35 & 91.4 & .620 & 36.85 & 20.85 & 32.40 & 2.82 & 4.10 & 7.97 & 5.04 \\
\hline 36 & 91.4 & .867 & 55.05 & 32.36 & 35.90 & 2.55 & 2.93 & 7.32 & 3.31 \\
\hline
\end{tabular}




\section{REFERENCES}

1. Boehm, R. F., and Jacobs, H. R., "Feasibility Study of the Application of Direct Contact Heat Exchangers to Power Cycles Utilizing Goethermal Brines," Energy Research and Development Administration, Report No. E-(11-1)2601, July 1974.

2. Jacobs, H. R., and Fannar, H., "Direct Contact Condensers - A Literature Survey," Energy Reserach and Development Administration, Report No. DEE/1523-3, February 1977.

3. Lackey, K. L., "Direct Contact Condensation with Two Immiscible Fluids," U.S. Atomic Energy Commission, UCRL 10339, 1962.

4. Wilke, C. T., et al, "Direct Contact Heat Transfer for Sea Water Evaportation," Chemical Engineering Progress, Vol. 59, No. 12, December 1963, pp. 69-75.

5. Higbie, R., "The Rate of Absorption of a Pure Gas Into a Still Liquid During Short Periods of Exposure," Transactions of the American Institute of Chemical Engineers, Vo1. 31, 1935, pp. 365389.

6. Sherwood, T. K., and Holloway, A. L., "Performance of Packed Towers - Liquid Film Data for Several Packings," Transactions of the American Institute of Chemical Engineers, Vol. 36, 1940, pp. 39-70.

7. Harriott, P., and Wiegandt, H., "Countercurrent Heat Exchanger with Vaporizing Immiscible Transfer Agent," A.I.Ch.E. Journal, Vol.10, No. 5 , pp. 755-758.

8. Cheng, C. T., "Direct Contact Condensation in a Packed Tower," M.S. Thesis, University of California at Berkeley, 1963.

9. Tamir, A., and Rachmilev, I., "Direct Contact Condensation of an Immiscible Vapor on a Thin Film of Water," Int. $J$. Of Heat and Mass Transfer, Vo1. 17, 1974, pp. 1241-1251.

10. Maa, J. R., and Hickman, K., "Direct Contact Condensation of Steam on a Modified 0il Coolant," Desalination, Vol. 10, 1972, pp. 95-111.

11. Tamir, A., and Taitel, Y., "Diffusion to Flow Down an Incline with Surface Resistance," Chemical Engineering Science, Vol. 26, 1971, pp. 799-808. 
12. Sykes, J. A., and Marchello, M., "Condensation of Immiscible Liquids on Horizontal Tube," Ind. Eng. Chem. Process Des. Develop., Vol. 9, No. 1, January, 1970, pp. 63-71.

13. Rai, V. C., and Pinder, K. L., "Direct Contact Condensation of Steam in a Packed Column with Immiscible Heat Transfer Agents," Canadian Journal of Chemical Engineering, Vol. 45, 1967, pp. 170174.

14. Hu, S. C., "Direct Contact Gasoline Condenser," Petroluem Engineering, Vol. 28, No. 1, 1956, pp. 12-18.

15. Wilke, C. R., "Estimation of Liquid Diffusion Coefficients," Chemical Engineering Process, Vol. 45, No. 3, 1949, pp. 218-224.

16. Sherwood, T. K., Shipley, G. H., and Holloway, F.A.L., "Flooding Velocities in Packed Columns," Ind. and Eng. Chem., Vol. 30, 1938, pp. 765-769.

17. Eckert, J. S., "Selecting the Proper Distillation Column Packing," Chemical Engineering Proces, Vol. 66, No. 3, 1970, pp. 39-44.

18. Olander, D. R., "Design of Direct Contact Cooler-Condensors," Ind. and Eng. Chem., Vo1. 53, No. 2, February, 1961, pp. 121-126.

19. Bras, G. H. P. "Design Direct Contact Coolers Quickly," Petroleum Refiner, Vo1. 35, No. 12, December 1956, pp. 215-221.

20. Fair, J. R., "Designing Direct-Contact Coolers/Condensers," Chemical Engineering, Vol. 79, June 1972, pp. 91-100.

21. Jacobs, H. R., "Theoretical Consideration of the Evaporation of a Drop Rising through an Immisible Continuous Medium," 78 IHTC-55, Submitted for presentation at the Sixth International Heat Transfer Conference, August 1978, Toronto, Canada.

22. Shuiman, H. L., Ulirich, C. F., and Wells, N., "Performance of Packed Columns," A.I.Ch.E. Journal, Vol. 1, No. 2, 1955, pp. 247264.

23. Bernhardt, S. H., Sheridan, J. J., Westwater, J.W., "Condensation of Immiscible Mixtures," A.I.Ch.E. Symp., Ser. 68, 1972, pp. 27-27.

24. Lynn, S., Straatemeier, J. R., and Kramers, H., "Absorption Studies In the Light of the Penetration Theory," Chemical Engineering Science, Vol. 4, 1955, PP. 63-67. 